\title{
Corruption and Transparency in a Growth Model.
}

\author{
Christopher J. Ellis and John Fender* \\ Preliminary Draft \\ June 2003.
}

\begin{abstract}
We develop a Ramsey type model of economic growth in which the "Engine of Growth" is public capital accumulation. Public capital is a public good, and is financed by taxes on private output. The government may either use the taxes gathered to fund public capital accumulation or consume the resourses itself; that is engage in corruption. There is an irreducable level of endogenously determined corruption which constitutes rents for which potential governments compete. This competition takes the form of choosing a time path for public capital invesment, which implies time paths for output and household consumption.

We study both the model's steady state, and dynamical behavior along the saddle path. The predictions of our theory accord well with the existant empirical evidence on the relationships between the level and growth rate of output, corruption, public investment and fiscal transparency. Our analysis also does a good job of explaining the transition experiences of several Eastern European economies.
\end{abstract}

*Department of Economics, University of Oregon, Eugene, OR 97405 USA and Department of Economics, The University of Birmingham, UK. Keywords: Corruption, Growth, Public Capital.

JEL classification:

Acknowledgements: The authors wish to thank Shankha Chakraborty, John Bennett, George Evans, Yuan $\mathrm{Xu}$, Seppo Honkapohja, Toke Aidt, and Javier Rosenbleuth for comments and suggestions. 


\section{Introduction.}

There exists persuasive statistical evidence of significant links between corruption, fiscal transparency, investment, and economic growth. Mauro [13] demonstrates that negative relationships exist between corruption and growth, corruption and measures of both private and total investment, and between corruption and the level of GDP. Tanzi and Davoodi [22] find a strong positive relationship between corruption and public investment ${ }^{1}$. Generally empirical studies reveal that countries that are more corrupt and/or less fiscally transparent tend to experience slower growth rates and lower levels of per capita GDP ${ }^{2}$. Tanzi [23] provides a nice survey of the literature and associated evidence ${ }^{3}$. While numerous empirical studies have documented these relationships, they have received little theoretical analysis. Of the few theoretical works in this area perhaps the most noteworthy are Mauro [15], Ehrlich and Lui [8], and Barreto [4] each of whom has developed a distinct growth model that incorporates corruption. Mauro (op. cit.), building on the work of Andvig and Moene [3], in which the probability of an individual act of corruption being detected and punished is decreasing in the overall level of corruption, looks at how multiple equilibria may be used to explain high and low steady state levels of corruption. Ehrlich and Lui also develop a model of multiple equilibria, but with endogenous growth, in which consumer/bureaucrats may invest in human capital or political (rent seeking) capital. Somewhat differently Barreto's (op. cit.) work incorporates corruption into a neoclassical growth model in which government agents extract rents by acting as monopoly suppliers of a public good. The corrupt agents are constrained from extracting all rents by the possibility of being caught and punished. The contribution of this paper differs from those of Mauro (op. cit.), Ehrlich and Lui (op. cit.) and Barreto (op. cit.) quite substantially. Conceptually we place greater emphasis on the role of government behavior, most particularly we stress the importance for explaining corruption of the level of transparency in the fiscal system ${ }^{4}$. In our model competition between potential optimizing governments is motivated by the desire to capture the corruption rents generated from a lack of fiscal transparency, yet, as we shall demonstrate, competition does not eliminate these rents. This contrasts with the approach of Barreto where the government's agents act monopolistically and where rents are only constrained from above by the threat that corruption will be detected and punished. Central to our analysis will be the role played by public capital accumulation in economic growth, this is similar to Barreto but contrasts with Mauro and Ehrlich and Lui who emphasis private and human capital accumulation respectively. Here, the necessity in production of public capital (a public good), both provides a rationale for the existence of government, and, given that it has to be financed via taxes, the opportunity for corruption.

We offer a tractable framework for analyzing both the steady state and adjustment paths of a dynamic economy in which the relationships between corruption, the level of output, and its growth rate depend on the level of fiscal transparency and the economy's deep parameters. Our approach is closest in spirit to the work of Acemoglu and Verdier [2], who examine the trade off between corruption and market failures in a static model. We, like they, recognize that a theory of corruption needs to explicitly take into account the costs and benefits of government. Corruption may be a cost, but governments also yield benefits as they supply public and private goods to the economy. The main difference between our analysis and that of Acemoglu and Verdier (other than the obvious dynamic/static distinction) is that there is a principal agent problem at the core of their work. They assume that the government consists of a benevolent social planner who is unable to perfectly monitor the actions of it's corrupt agents. We assume that both the government and bureaucracy are comprised of rational self-interested agents, and subsume them into one corrupt entity; "government". We make this assumption because, while there are many interesting features of corruption that may be explained by an agency model, it is unclear to us why the government should be regarded as purely benevolent, and the bureaucracy as purely rent-seeking. Our approach is to introduce endogenous corruption into a variant of the Ramsey growth model. We accomplish this by assuming that a government taxes private producers and uses the resources to either supply public capital

\footnotetext{
${ }^{1}$ Tanzi and Davoooli are skeptical about there being a positive relationship between corruption, public investment, and growth; citing the poor quality of public investment projects in highly corrupt economies as a negative factor.

${ }^{2}$ At its fiftieth meeting in Washington, D.C., on April 16, 1998, the Interim Committee of the Board of Governors of the International Monetary Fund, in response to this growing body of evidence, adopted the Code of Good Practices on Fiscal Transparency Declaration on Principles.

${ }^{3}$ Since, by definition, corruption cannot accurately be directly measured, empirical studies of corruption rely on indexes of perceptions of corruption typicaly obtained from surveys of foreign businessmen.

${ }^{4}$ Neither Ehrlich and Lui (op. cit.) nor Mauro model the government as an optimizing agent. In Ehrlich and Lui's analysis the government is not formally modelled. In Mauro, al la Barro (op.cit.), government expenditures follow a simple proportionate rule, and taxes are set to balance the budget. In Barreto there is an agent that represents the government, but this agent is constrained by detection probabilities and punishments set by an agent that is not modeled.
} 
(roads, education, an effective judicial system, and the like) or simply, corruptly, consumes the taxes itself. ${ }^{5}$

In our model we have a tension, much like that discussed by Acemoglu and Verdier (op cit.), between the need for the government to rectify a market failure, here to supply a public good, and the opportunity that this provides for corruption. To model this we assume that there is a time lag in public capital production. This is taken to imply that it cannot be verified until a later date whether the government has applied tax revenues to pubic capital accumulation or simply consumed them. This production lag, which can also be interpreted as the degree of transparency in the fiscal system, or perhaps the quality of economic institutions, introduces a level of irreducable corruption into the economy. Any government always has the option of corruptly pocketing all tax revenues up until the point of detection. While the present discounted value of corruption payments cannot be reduced below their irreducable level, their intertemporal distribution is not fixed, a government may, for example, steal everything for two years before being overthrown in some manner, or, it may take smaller payments over the infinite horizon and remain in power. We argue that the existence of an irreducable level of corruption provides the incentives for potential governments to compete for office. Governmental competition takes the form of offering time paths of consumption and hence utility to the private sector ${ }^{6}$. This works like the model of competitive corruption introduced by Schleifer and Vishny [21], except that instead of driving corrupt payments to zero, competition between corrupt potential governments leads to the maximization of the present discounted value of private sector utility subject to a constraint imposed by the level of irreducable corruption. We find that this simple variant of the Ramsey growth model does a good job in explaining the results found in the empirical literature on the relationships between corruption, the level and growth rate of GDP, public investment, and fiscal transparency. Further, it also allows us to gain some insights into the problems encountered by transition economies

It should be noted that while fiscal transparency is an exogenous variable in our model, determined by assumptions on the production lag, the levels of corruption, public investment and growth are all endogenous. Corruption does not cause growth of visa versa, rather both are simultaneously generated from deep preference and technology parameters

\section{Structure of the Model.}

\subsection{The Economy.}

For simplicity we assume the economy consists of the government and two consumer/producers. The consumer/producers are identical except that each supplies a heterogenous labor input, $l^{i}(t) i=1$, each of which is essential, and combine to produce effective labor according to $l(t)=\min _{i}\left[l^{i}(t)\right]$.

Output, $y(t)$, is produced using effective labor, $l(t)$, and, as in Barro [5] public capital, $p(t)$, according to the Cobb-Douglas production technology

$$
y(t)=f(l(t), p(t))=l(t)^{\alpha} p(t)^{\beta},
$$

where $0<\alpha, \beta<1$. Public capital is a public good that is supplied to the economy by the government according to the simple linear technology

$$
\frac{d p(t)}{d t}=\dot{p}(t)=\tau(t-\omega)-b(t-\omega)-\delta p(t)
$$

where $\tau(t-\omega)$ represents taxes paid at an interval of length $\omega$ in the past, $b(t-\omega)$ represents the portion of past tax payments that were corruptly appropriated by the government for its own consumption purposes, and $\delta$ is the depreciation rate of public capital. The interval $\omega$ is hence the length of the production lag, and, as we shall subsequently argue, may also be interpreted as the degree of fiscal transparency in the economy.

\footnotetext{
${ }^{5}$ Reimikka and Svensson [19] provide considerable insight into this problem. Studying "leakages" from planned disbursements to public primary schools in Uganda they find that over the time period 1991-95 only $13 \%$ of disbursed funds reached their intended destinations. The residual $87 \%$ was either redirected or stolen by local government officials. In response to this theft the central government publicised the amount of disbursments actually made to local areas, that is they increased transparency. The result was an increase in funds that reached their intended destinations to $90 \%$ in 1999.

${ }^{6}$ This is somewhat in the spirit of the "Citizen Candidate" model of Osborne and Slivinsky [17] and Besley and Coate [6]. While candidates do not compete in the sense of locating on a line representing heterogeneous preferences, any candidate that fails to offer the equilibrium time path of consumption to the population is immediately replaced.
} 
In this analysis, as in Mauro [15], corruption is modelled as direct theft of government revenues or expenditures. Mauro (op. cit.) and Abbott [1] give some colorful examples of such activities. ${ }^{7}$ However, we do not wish this feature of the model to be taken too literally, rather we view our analysis as potentially compatible with many microeconomic mechanisms by which government or bureaucratic corruption extracts resources from the economy. Our focus is on modelling the macroeconomic relationships between corruption, public investment, transparency, and growth ${ }^{8}$. To accomplish our goal the key requirement is that the opportunity cost of governmental or bureaucratic corruption is public capital accumulation. The reader interested in the details of the various mechanisms by which corruption distorts resource allocations in an economy is referred to the excellent survey of Tanzi (op. cit.).

The objective of the consumer/producers is to maximize the present discounted value of utility derived from consumption, $c^{i}(t)$, and leisure, $-l^{i}(t)$, given preferences described by

$$
\operatorname{Max} \int_{0}^{\infty} u^{i}(t) e^{-r t} d t=\int_{0}^{\infty} u\left(c^{i}(t), l^{i}(t)\right) e^{-r t} d t=\int_{0}^{\infty}\left[c^{i}(t)-l^{i}(t)\right]^{\theta} e^{-r t} d t
$$

where $0<\theta<1$ is the intertemporal substitution parameter and, $r$ is the discount rate. We assume that the instantaneous budget constraint

$$
\sum_{i} c^{i}(t)=y(t)-\tau(t)
$$

must be satisfied. For simplicity we assume $y(t)$ is non-storable, and that the consumer/producers have the choice of either to work $l^{i}(t)=1$, or not $l^{i}(t)=0$. This implies that $c^{i}(t) \geq l^{i}(t)=1$, may be viewed as the consumer/producers' instantaneous participation constraint.

The objective of the government is to maximize the present discounted value of corruption payments

$$
\int_{0}^{\infty} b(t) e^{-r t} d t
$$

Exactly how the government may pursue this objective depends on the nature of the political process. We discuss this next.

\subsection{The Political Process.}

We assume the political process works as follows. At any instant $t$ a particular government holds power. This government is in office because at some point in the past it made a promise to deliver a time path of consumption to the consumer/producers by setting particular time paths for taxes and public capital investment. At each instant any government has the option of either honoring this promise or defecting and pocketing all of the tax revenues as corruption. If it chooses the first option the same set of options obtain at the next instant, if it chooses the second option it knows that it is not investing in the public capital necessary to deliver the promised consumption stream, and that this will be detected after an interval of length $\omega$ (that is after the production lag). In the case of government defection each consumer/producer can respond either by choosing to continue working or to withdraw their labor. This latter option might be interpreted as engaging in political protest. The consumer/workers hence play a game with the following payoff matrix

\begin{tabular}{|c|c|c|c|}
\hline \multicolumn{2}{|c|}{} & \multicolumn{2}{|c|}{ Consumer/Producer\#2 } \\
\cline { 3 - 4 } \multicolumn{2}{|c|}{} & Work & Withdraw \\
\hline \multirow{2}{*}{$\begin{array}{c}\text { Consumer/Producer } \\
\# 1\end{array}$} & Work & $0,0^{9}$ & $\int_{0}^{\infty}[-1]^{\theta} e^{-r t} d t, 0$ \\
\cline { 2 - 4 } & Withdraw & $0, \int_{0}^{\infty}[-1]^{\theta} e^{-r t} d t$ & 0,0 \\
\hline
\end{tabular}

\footnotetext{
${ }^{7}$ Abbott describes the behavior of Luckner Cambronne a political associate of Duvalier in Haiti. Cambronne stole all the materials designated to build a rail link from Port-au-Prince to Verrettes via St. Marc sold them for scrap and pocketed the proceeds.

${ }^{8}$ See Tanzi and Davoodi [22] for a recent discussion and assessment of these mechanisms.

${ }^{9}$ If the players choose $\{$ work, work $\}$ in response to a defection by the government, then clearly the government will set the tax at $\tau(t)=y(t)-2 \forall t$, with $c^{i}(t)=l^{i}(t)=1 i=1,2$, and the players will each recieve $u(t)=0 \forall t$.
} 
There are clearly two equilibria to this game $\{$ Work, Work $\}$ and $\{$ Withdraw, Withdraw $\}$. Suppose now that each consumer/producer believes with probability 1 that the other will play withdraw if the government defects on a promise. It follows that in the case of a government defection these beliefs will coordinate the players on the $\left\{\right.$ Withdraw, Withdraw \} equilibrium ${ }^{10}$. In this equilibrium output, taxes and corruption payments will be zero. Hence the beliefs plus the \{Withdraw, Withdraw equilibrium serve as a punishment or trigger strategy to prevent government defections. However, the public are aware that any government always has the "take the money and run" option, that is steal everything for an interval of length $\omega$ and then quit, it thus follows that they will believe only those promises which are credible in the sense that at each instant they satisfy the corruption constraint

$$
\int_{j=t}^{\infty} b(j) e^{-r j} d j \geq \int_{j=t}^{t+\omega} \tau(j) e^{-r j} d j \forall t .
$$

The time path of corruption that the government follows, and thus the implied investment and consumption promises, cannot yield a time-path for corruption payments of less present discounted value than the option of appropriating all taxes until they are detected. This is the level of irreducable corruption in the economy. Political competition between potential governments for these rents ensures that this constraint holds with an equality. Further, the competition for $\int_{j=t}^{t+\omega} \tau(j) e^{-r j} d j$ also ensures that the time paths of $b(t)$ and $\tau(t)$ chosen by the government maximize the present discounted value of the consumer/producers' utility.

Hereafter the distinction between the two consumer/producers plays no essential role in the analysis. Hence we shall combine the two into a "household sector" with consumption $c(t)$, labor $l(t)$ and utility $u(t)$. This has absolutely no implications for any of our results, but saves greatly on algebra and notation.

\section{The Dynamic Optimization Problem.}

Given the economic and political structure outlined above the government's optimization problem reduces to maximizing the present discounted value of the utility stream enjoyed by the household sector, or

$$
\operatorname{Max} \int_{0}^{\infty}\left[l(t)^{\alpha} p(t)^{\beta}-\tau(t)-l(t)\right]^{\theta} e^{-r t} d t,
$$

by choosing the paths of $\{\tau\}$ and $\{b\}$ with $l(t)=1$. Subject to the public capital accumulation constraint

$$
\dot{p}(t)=\tau(t-\omega)-b(t-\omega)-\delta p(t),
$$

and the requirement that it satisfy the corruption irreducability constraint

$$
\int_{j=t}^{\infty} b(j) e^{-r j} d j=\int_{j=t}^{t+\omega} \tau(j) e^{-r j} d j \forall t .
$$

This problem is a variant of the isoperimetric problem from optimal control theory, with the additional complication that the optimization requires the use of "delayed controls" ${ }^{11}$ Our solution method is to take the derivative of the corruption constraint with respect to time, and then use this expression to transform the problem into a standard form in which the controls are not delayed. We then check (see the appendix) that the time paths derived as solutions to the resultant optimization problem do indeed satisfy the original integral constraint. Following this approach we differentiate the corruption irreducability constraint with respect to time to yield

$$
-b(t) e^{-r t}=\tau(t+\omega) e^{-r(t+\omega)}-\tau(t) e^{-r t} .
$$

Dividing (10) $e^{-r t}$ and then lagging the resultant expression back an interval of length $\omega$ yields

$$
-b(t-\omega)=\tau(t) e^{-r \omega}-\tau(t-\omega) .
$$

\footnotetext{
${ }^{10}$ We are assuming that if the government does not defect the consumer/producers are coordinated on the $\{$ Work, Work $\}$ equilibrium. Note also that if the govenment is not defecting the payoffs to the \{Work, Work \} equilibrium.will be significantly higher.

${ }^{11}$ See Rosenblueth [20] for an analysis of this class of problems.
} 
Substituting (11) into the differential equation constraint (8) yields

$$
\dot{p}(t)=\tau(t) e^{-r \omega}-\delta p(t) .
$$

Hence the problem reduces to

$$
\begin{gathered}
\operatorname{Max} \int_{0}^{\infty}\left[p(t)^{\beta}-\tau(t)-1\right]^{\theta} e^{-r t} d t \\
\text { s.t. } \dot{p}(t)=\tau(t) e^{-r \omega}-\delta p(t)
\end{gathered}
$$

Rearranging using the private good production function (1), and the flow budget constraint (4), allows the problem to be rewritten in the more familiar form.

$$
\begin{gathered}
\operatorname{Max} \int_{0}^{\infty}[c(t)-1]^{\theta} e^{-r t} d t \\
\text { s.t. } \dot{p}(t)=p(t)^{\beta} e^{-r \omega}-c(t) e^{-r \omega}-\delta p(t),
\end{gathered}
$$

which is a variant of the Ramsey version of the neoclassical growth model.

The current value Hamiltonian for the problem (14) can be written

$$
\operatorname{Max} H=[c(t)-1]^{\theta} e^{-r t}+\xi(t)\left[p(t)^{\beta} e^{-r \omega}-c(t) e^{-r \omega}-\delta p(t)\right] .
$$

Using standard techniques (see the appendix), it can be shown that the solution to this optimization problem may be expressed as the following pair of differential equations

$$
\dot{p}(t)=p(t)^{\beta} e^{-r \omega}-c(t) e^{-r \omega}-\delta p(t),
$$

and

$$
\dot{c}(t)=\left(\frac{1}{\theta-1}\right)\left[\delta-\beta p(t)^{\beta-1} e^{-r \omega}+r\right][c(t)-1] .
$$

We may now represent this dynamic system on a phase diagram by noting that the stationaries are given by

$$
c(t)=p(t)^{\beta}-\frac{\delta p(t)}{e^{-r \omega}}
$$

and

$$
c(t)=1 \text { or } p(t)=\left(\frac{\beta e^{-r \omega}}{\delta+r}\right)^{\frac{1}{1-\beta}}
$$


c(t)

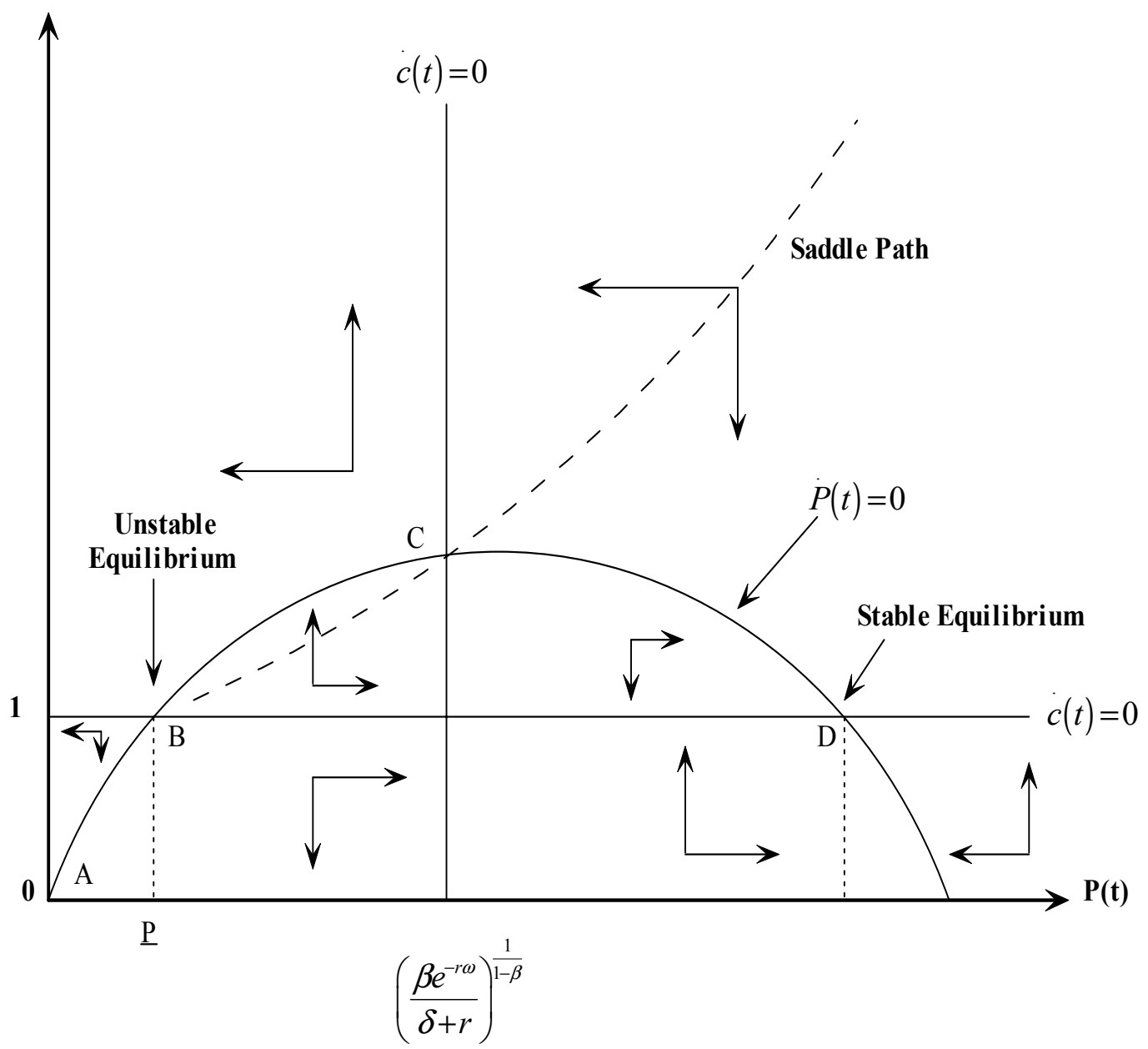

Figure 1: The Phase Diagram.

As the figure 1 reveals the model displays four steady states, three associated with positive levels of consumption and the public capital stock, and the "shut down" equilibrium, A, where the household sector decides not to work and the economy collapses to zero capital and output. Amongst the three positive consumption and public capital stock equilibria we immediately see that the low public capital stock equilibrium B is unstable, the high public capital stock equilibrium D is a stable source, and the high consumption level equilibrium $\mathrm{C}$ is a stable saddle (details of the dynamics may be found in the appendix). Notice that for any initial public capital stock $P(0)>\underline{P}$ the saddle path yields levels of consumption along its entire path that exceed the consumption level at the stable source. It follows that a government competing for the irreducable corruption payoff will offer the consumption path associated with the saddle path. This can be achieved by appropriately selecting the paths of taxes and investment.

Solving the dynamic system for the saddle path stable steady state $\mathrm{C}$ yields

$$
\bar{c}=\left[\left(\frac{\beta}{\delta+r}\right)^{\frac{\beta}{1-\beta}}-\delta\left(\frac{\beta}{\delta+r}\right)^{\frac{1}{1-\beta}}\right]\left(e^{-r \omega}\right)^{\frac{\beta}{1-\beta}},
$$

and

$$
\bar{p}=\left(\frac{\beta e^{-r \omega}}{\delta+r}\right)^{\frac{1}{1-\beta}} .
$$


Linearizing the dynamic system around this steady state provides

$$
\dot{p}(t)-\left[\beta \bar{p}^{\beta-1} e^{-r \omega}-\delta\right][p(t)-\bar{p}]+\left[e^{-r \omega}\right][c(t)-\bar{c}]=0,
$$

and

$$
\dot{c}(t)+\left[\left(\frac{1}{\theta-1}\right)\left(\beta(\beta-1) \bar{p}^{\beta-2} e^{-r \omega}\right)(\bar{c}-1)\right][p(t)-\bar{p}]-\left[\left(\frac{1}{\theta-1}\right)\left(\delta-\beta \bar{p}^{\beta-1} e^{-r \omega}+r\right)\right][c(t)-\bar{c}]=0 .
$$

Solving this linearized system gives

$$
p(t)=(p(0)-\bar{p}) e^{\lambda_{2} t}+\bar{p}=e^{\lambda_{2} t} p(0)+\left(1-e^{\lambda_{2} t}\right) \bar{p}
$$

and

$$
c(t)=-\left(\frac{\lambda_{2}-r}{e^{-r \omega}}\right)(p(0)-\bar{p}) e^{\lambda_{2} t}+\bar{c}
$$

where $\lambda_{2}$ is the stable root of the characteristic equation and $\bar{p}$ and $\bar{c}$ are the particular integrals (20) and (21) as defined above. Further, we can obtain the linear approximation to the stable branch (details in the appendix) as

$$
c(t)=\left[\bar{c}+\left(\frac{\lambda_{2}-r}{e^{-r \omega}}\right) \bar{p}\right]-\left(\frac{\lambda_{2}-r}{e^{-r \omega}}\right) p(t) .
$$

Armed with the solution equations and the equation of the stable branch, we can now investigate the relationships between corruption, the level and growth rate of output, public investment, and transparency.

\section{Corruption in the Long Run: Steady State Relationships.}

\subsection{Comparative Statics.}

In this model it is not the case that corruption has a causal effect on either the level or rate of growth of output in the economy. The steady state levels of corruption, output, consumption, and public investment all derive from "deep" parameters of the model. Hence we cannot perform comparative statics exercises to observe the effects of corruption on a particular variable of interest. Instead to obtain an understanding of the determinants of corruption in the steady state we examine three measures of relative corruption, the share of corruption in total output, $\frac{\bar{b}}{\bar{y}}$, the share of corruption in government revenues, $\frac{\bar{b}}{\bar{\tau}}$, and the ratio of corruption to consumption, $\frac{\bar{b}}{\bar{c}}$. Each of these three measures gives a slightly different insight into the prevalence of corruption in the steady state, and how that prevalence is explained. The share of corruption in total output provides a measure of the share of societies resources devoted to corruption. The ratio of corruption to taxes gives an indication of the rate at which the government steals the resources available to it, while the ratio of corruption to consumption gives us an indication of the relative resources devoted to household sector and public sector consumption. It is straightforward to show these measures may be written (again see the appendix) as

$$
\begin{gathered}
\frac{\bar{b}}{\bar{y}}=\left(1-e^{-r \omega}\right)\left(\frac{\delta \beta}{\delta+r}\right), \\
\frac{\bar{b}}{\bar{\tau}}=\left(1-e^{-r \omega}\right),
\end{gathered}
$$

and

$$
\frac{\bar{b}}{\bar{c}}=\frac{\left(1-e^{-r \omega}\right) \delta}{\frac{\delta+r}{\beta}-\delta} .
$$

From these definitions simple differentiation reveals 


\begin{tabular}{ccc}
\hline Corruption-Output Ratio & Corruption-Tax Revenue Ratio & Corruption-Consumption Ratio \\
\hline$\frac{\partial\left(\frac{\bar{b}}{\bar{y}}\right)}{\partial \delta}=\frac{\beta r}{(\delta+r)^{2}}\left(1-e^{-r \omega}\right)>0$ & $\frac{\partial\left(\frac{\bar{b}}{\tau}\right)}{\partial \delta}=0$ & $\frac{\partial\left(\frac{\bar{b}}{\bar{c}}\right)}{\partial \delta}=\frac{\left(1-e^{-r \omega}\right)\left(\frac{\delta+r}{\beta}\right)}{\left(\frac{\delta+r}{\beta}-\delta\right)^{2}}>0$ \\
$\frac{\partial\left(\frac{\bar{b}}{\bar{y}}\right)}{\partial r}=\left(\frac{\delta \beta}{\delta+r}\right)\left[\omega e^{-r \omega}-\frac{1-e^{-r \omega}}{\delta+r}\right] \gtreqless 0$ & $\frac{\partial\left(\frac{\bar{b}}{\tau}\right)}{\partial r}=\omega e^{-r \omega}>0$ & $\frac{\partial\left(\frac{\bar{b}}{\bar{c}}\right)}{\partial r}=\frac{\omega e^{-r \omega} \delta\left(\frac{\delta+r}{\beta}-\delta\right)-\frac{1}{\beta}\left(1-e^{-r \omega}\right) \delta}{\left(\frac{\delta+r}{\beta}-\delta\right)^{2}} \gtreqless 0$ \\
$\frac{\partial\left(\frac{\bar{b}}{\bar{y}}\right)}{\partial \omega}=r e^{-r \omega}\left(\frac{\delta \beta}{\delta+r}\right)>0$ & $\frac{\partial\left(\frac{\bar{b}}{\tau}\right)}{\partial \omega}=r e^{-r \omega}>0$ & $\frac{\partial\left(\frac{\bar{b}}{\bar{c}}\right)}{\partial \omega}=\frac{\beta \omega e^{-r \omega}}{\delta+r-\beta \delta}>0$ \\
$\frac{\partial\left(\frac{\bar{b}}{\bar{y}}\right)}{\partial \beta}=\left(1-e^{-r \omega}\right)\left(\frac{\delta}{\delta+r}\right)>0$ & $\frac{\partial\left(\frac{\bar{b}}{\tau}\right)}{\partial \beta}=0$ & $\frac{\partial\left(\frac{\bar{b}}{\bar{c}}\right)}{\partial \beta}=\frac{\beta\left(1-e^{-r \omega}\right) \delta}{\delta+r-\beta \delta}>0$ \\
\hline
\end{tabular}

and

\begin{tabular}{ccc}
\hline Corruption-Output Ratio & Corruption-Tax Revenue Ratio & Corruption-Consumption Ratio \\
\hline$\frac{\partial^{2}\left(\frac{\bar{b}}{\bar{y}}\right)}{\partial \delta^{2}}=-\frac{\beta r}{(\delta+r)^{3}}\left(1-e^{-r \omega}\right)<0$ & $\frac{\partial^{2}\left(\frac{\bar{b}}{\tau}\right)}{\partial \delta^{2}}=0$ & $\frac{\partial^{2}\left(\frac{\bar{b}}{\bar{c}}\right)}{\partial \delta^{2}}=\frac{\left(1-e^{-r \omega}\right)\left(\frac{1}{\beta}\right)}{\left(\frac{\delta+r}{\beta}-\delta\right)^{2}}\left[1-\frac{2\left(\frac{\delta+r}{\beta}\right)}{\left(\frac{\delta+r}{\beta}-\delta\right)}\right]<0$ \\
$\frac{\partial^{2}\left(\frac{\bar{b}}{\bar{y}}\right)}{\partial r^{2}}=-2\left[\frac{\delta \beta}{(\delta+r)^{2}}\right]\left[\omega e^{-r \omega}-\frac{1-e^{-r \omega}}{\delta+r}\right]$ & $\frac{\partial^{2}\left(\frac{\bar{b}}{\tau}\right)}{\partial r^{2}}=-\omega^{2} e^{-r \omega}<0$ & $\frac{\partial\left(\frac{\bar{b}}{\bar{c}}\right)}{\partial r}=\frac{\omega e^{-r \omega} \delta\left(\frac{\delta+r}{\beta}-\delta\right)-\frac{1}{\beta}\left(1-e^{-r \omega}\right) \delta}{\left(\frac{\delta+r}{\beta}-\delta\right)^{2}} \gtreqless 0$ \\
$-\left(\frac{\delta \beta}{\delta+r}\right) \omega^{2} e^{-r \omega \gtreqless 0}$ & $\frac{\partial^{2}\left(\frac{\bar{b}}{\bar{\tau}}\right)}{\partial \omega^{2}}=-r^{2} e^{-r \omega}<0$ & $\frac{\partial^{2}\left(\frac{\bar{b}}{\bar{c}}\right)}{\partial \omega^{2}}=\left(\frac{\beta e^{-r \omega}}{\delta+r-\beta \delta}\right)(1-r \omega) \gtreqless 0$ \\
$\frac{\partial^{2}\left(\frac{\bar{b}}{\bar{y}}\right)}{\partial \omega^{2}}=-r^{2} e^{-r \omega}\left(\frac{\delta \beta}{\delta+r}\right)<0$ & $\frac{\partial^{2}\left(\frac{\bar{b}}{\tau}\right)}{\partial \beta^{2}}=0$ & $\frac{\partial^{2}\left(\frac{\bar{b}}{\bar{c}}\right)}{\partial \beta^{2}}=\frac{\left(1-e^{-r \omega}\right) \delta(\delta+r)}{(\delta+r-\beta \delta)^{2}}>0$ \\
$\frac{\partial^{2}\left(\frac{\bar{b}}{\bar{y}}\right)}{\partial \beta^{2}}=\left(1-e^{-r \omega}\right)\left(\frac{\delta}{\delta+r}\right)=0$ & Table 2: Steady State - Second Order Effects.
\end{tabular}

To understand these results it is helpful to first elucidate the intuition behind the steady state. Partially this is standard. In the steady state the economy has achieved a level of capital stock such that the marginal cost to the household sector of foregoing another unit of current consumption is exactly equal to the present discounted value of additional future consumption that this "savings" generates, and the implied additions to the capital stock exactly offset depreciation. Our analysis differs from the standard story in that the capital stock is public capital, additions to which are financed via taxes. These taxes are transformed into public capital only after a production lag, and only after some proportion has been corruptly appropriated by the government.

Rather than labor through a taxonomy of all of these results, we shall concentrate on those that, in our view, seem to be of the most economic interest. Perhaps of greatest interest are the effects of changes in the production lag and thus fiscal transparency. Kopits and Craig [11] define fiscal transparency as

"... openness toward the public at large about government structure and functions, fiscal policy intentions, public sector accounts, and projections. It involves ready access to reliable,comprehensive, timely, understandable, and internationally comparable information on government, activities ... so that the electorate and financial markets can accurately assess the government's financial position and the true costs and benefits of government activities, including their present and future economic and social implications".

In our analysis the level of transparency is described by the length of the production lag $\omega$. We see that all three measures of corruption are decreasing in transparency (increasing in the production lag, $\omega$ ). An increase in $\omega$ implies the length of the interval that defines the level of irreducable corruption necessarily increases. Hence at a given level of output and public capital stock it follows that additions to the pubic capital stock fall short of losses due to depreciation, and the marginal value of foregoing a unit of consumption today exceeds the present discounted value of the implied increase in future consumption. The steady state levels of output and the public capital stock thus fall. Now, as (27) indicates for a given $\omega$ a fall in $\bar{y}$ induces an equi-proportionate fall in $\bar{b}$, however since $\bar{b}$ is increasing in $\omega$ it follows that $\frac{\bar{b}}{\bar{y}}$ must rise. Since $\bar{\tau}$ and $\bar{c}$ are also both proportional to $\bar{y}$ these too must fall relative to $\bar{b}$. Inspection of table 2 reveals that transparency also has a decreasing marginal effect on the corruption-output and corruption-tax ratios and an ambiguous marginal effect on the corruptionconsumption ratio. The decreasing marginal effects on the corruption-output and corruption-tax ratios arise 
because as transparency decreases the steady state levels of the public capital stock and output decline. It follows that marginal increments to the production lag and therefore increases in the level of irreducable corruption decline at the margin. In simple terms the government can steal everything for a slightly longer period but the revenues available for theft at each instant are declining.

An alternative interpretation for changes in $\omega$ is that they proxy for changes in the quality of economic institutions. Following Olson [16], and Hall and Jones [9] [10] there is a considerable literature that seeks to explain the relative levels of GDP per worker across countries by comparing the quality of their economic institutions. Hall and Jones state

"Societies in which the economic environment encourages the diversion of output instead of its production produce much less output per worker. Diversion encompasses a wide range of activities, including theft, corruption, litigation, and expropriation."

Substituting (21) into (1) and differentiating with respect to $\omega$ provides.

$$
\frac{\partial \bar{y}}{\partial \omega}=-r\left(\frac{\beta}{1-\beta}\right)\left(\frac{\beta e^{-r \omega}}{\delta+r}\right)^{\frac{\beta}{1-\beta}}<0 .
$$

In as much as $\omega$ may be taken to reflect the quality of economic institutions, our model thus leads to a similar conclusion.

We also find the effects of an increase in the depreciation rate to be of interest. Tanzi and Davoodi (op. cit.) have reported that greater corruption is positively correlated with the quantity of public investment but argue that it is negatively correlated with its quality. One way to capture this claim is to assume that lower quality investments deteriorate more rapidly, require more upkeep, and thus may be represented by an increase in $\delta$. In this model the effect of $\delta$ on corruption as a share of output and the corruption-consumption ratio is not inconsistent with this evidence. From the first row of table 1 we see that an increase in the depreciation rate increases the share of corruption in total output and raises the corruption-consumption ratio, but leaves the share of corruption in government tax revenue unaffected. An increase in the depreciation rate implies that if the household sector gives up a unit of consumption today the public capital thus accumulated will degrade faster, and thus the future consumption stream obtained due to the contemporaneous sacrifice will be smaller. Hence the steady state levels of the public capital stock and output will decline. Yet the government makes more investments at the inferior quality level to provide itself with a greater opportunity for theft.

A third potentially interesting implication of our analysis concerns the effects of a change in the discount rate, $r$. While we do not explicitly model uncertainty in this analysis, we might wish to think of $r$ as incorporating a risk premium. If we then suggest that changes in $r$ might capture the effects of changes in the level of uncertainty in corruption, then from (1) and (21) we may obtain the following

$$
\frac{\partial \bar{y}}{\partial r}=-\left[\left(\frac{\beta}{1-\beta}\right)\left(\frac{\beta e^{-r \omega}}{\delta+r}\right)^{\frac{2 \beta-1}{1-\beta}}\left(\frac{\omega \beta e^{-r \omega}(\delta+r)+\beta e^{-r \omega}}{(\delta+r)^{2}}\right)\right]<0 .
$$

Hence if a rise in $r$ reflects an increased risk premium in response to a rise in the variance of corruption, then this reduces the steady state level of output. Further, as tables 1 and 2 indicate, our model predicts that increases in corruption risk unambiguously raise the steady state values of the corruption-tax revenue ratio and also increase the corruption-output and corruption-consumption ratios for low discount rates ${ }^{12}$. We are unaware of any studies that empirically explore these relationships. However, given that both the World Development Report [24] and Lambsdorff [12] stress the potential importance of the negative effects of corruption uncertainty on total investment, it is of interest to ask what other implications corruption uncertainty may have.

\section{The Dynamics of Corruption.}

Do countries become more or less corrupt as they grow? To investigate this issue we adopt the same measures as employed previously and examine the time paths of total corruption and the ratios of corruption to total output, tax revenues, and household sector consumption respectively.

\footnotetext{
${ }^{12}$ This can be verified by taking the limits of the two ratios as $r \rightarrow 0$, and then applying continuity.
} 


\subsection{Total Corruption.}

Along the stable branch to the saddle path equilibrium the level of corruption can be described by (see appendix)

$$
b(t)=\left(\lambda_{2}+\delta\right)(p(0)-\bar{p}) \lambda_{2} e^{\lambda_{2} t}\left[e^{r \omega}-e^{\lambda_{2} \omega}\right]+\delta \bar{p}\left(e^{r \omega}-1\right) .
$$

where $\lambda_{2}$ is the stable (negative) characteristic root. Differentiating this expression with respect to time demonstrates that total corruption evolves according to

$$
\dot{b}(t)=\left(\lambda_{2}+\delta\right)(p(0)-\bar{p})\left(\lambda_{2}\right)^{2} e^{\lambda_{2} t}\left[e^{r \omega}-e^{\lambda_{2} \omega}\right]>0,
$$

and differentiating with respect to time again provides

$$
\ddot{b}(t)=\left(\lambda_{2}+\delta\right)(p(0)-\bar{p})\left(\lambda_{2}\right)^{3} e^{\lambda_{2} t}\left[e^{r \omega}-e^{\lambda_{2} \omega}\right]<0 .
$$

We immediately see that along the stable branch corruption is increasing at a decreasing rate. This simply tells us that all else equal more mature economies should display higher absolute levels of corruption. However we are also concerned with the relative share of resources lost to corruption.

\subsection{Corruption as a Share of Output.}

Along the stable branch we can show that the evolution of the corruption-output ratio is determined by

$$
\left(\frac{b(t)}{y(t)}\right)=\left[\left(\lambda_{2}+\delta\right)(p(0)-\bar{p}) \lambda_{2} e^{\lambda_{2} t}\left[e^{r \omega}-e^{\lambda_{2} \omega}\right]+\delta \bar{p}\left(e^{r \omega}-1\right)\right]\left[e^{\lambda_{2} t} p(0)+\left(1-e^{\lambda_{2} t}\right) \bar{p}\right]^{-\beta},
$$

so differentiating with respect to time gives us

$$
\begin{aligned}
\left(\frac{\dot{b(t)}}{y(t)}\right)= & \left(\lambda_{2}+\delta\right)(p(0)-\bar{p})\left(\lambda_{2}\right)^{2} e^{\lambda_{2} t}\left[e^{r \omega}-e^{\lambda_{2} \omega}\right]\left[e^{\lambda_{2} t} p(0)+\left(1-e^{\lambda_{2} t}\right) \bar{p}\right]^{-\beta} \\
& -\beta\left[e^{\lambda_{2} t} p(0)+\left(1-e^{\lambda_{2} t}\right) \bar{p}\right]^{-(1+\beta)}[p(0)-\bar{p}] \lambda_{2} e^{\lambda_{2} t} \\
& \times\left[\left(\lambda_{2}+\delta\right)(p(0)-\bar{p}) \lambda_{2} e^{\lambda_{2} t}\left[e^{r \omega}-e^{\lambda_{2} \omega}\right]+\delta \bar{p}\left(e^{r \omega}-1\right)\right] \gtreqless 0 .
\end{aligned}
$$

Studying this differential equation (see the appendix for details) reveals that corruption can follow one of two possible types of time path characterized by either monotonic convergence of the steady state, or, for some parameterizations, overshooting, whereby the share of corruption in output rises rapidly and exceeds its steady state value before declining again.

These potential time paths are illustrated in figure 2 .

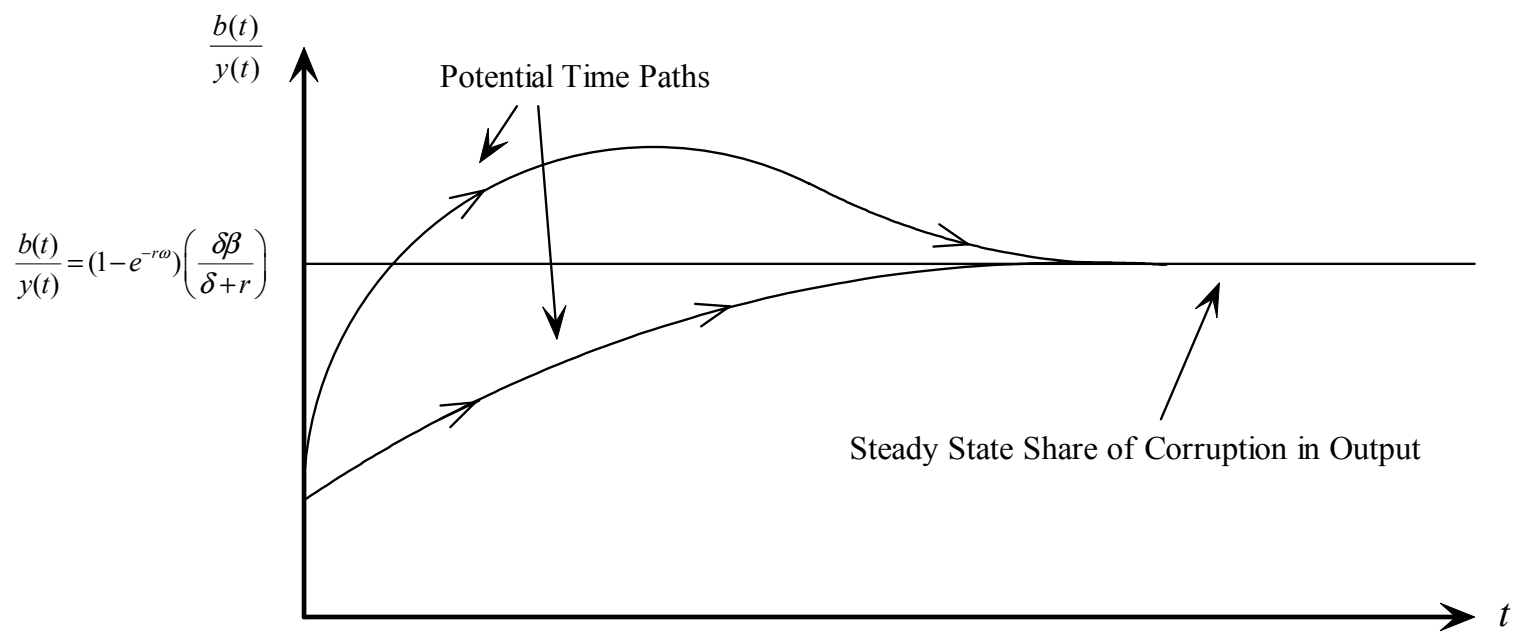

Figure 2: Corruption as a Share of Output. 
Since both the level of output and the absolute level of corruption increase at a decreasing rate as the system approaches the steady state from below along the saddle path, their ratio can rise or fall along any particular interval, but ultimately must become constant. The overshooting path tends to occur for higher values of $\beta$ and $\delta$.

\subsection{The Share of Taxes Corruptly Appropriated.}

We might also ask about the share of taxes that the government corruptly pockets along the convergent path or

$$
\frac{b(t)}{\tau(t)}=1-e^{-r \omega} \frac{\tau(t+\omega)}{\tau(t)}
$$

we know from (12) that $\tau(t)=\frac{\dot{p}(t)+\delta p(t)}{e^{-r \omega}}$. Now from (24) and its time derivative we have $\frac{\dot{p}(t)+\delta p(t)}{e^{-r \omega}}=\frac{\left(\lambda_{2}+\delta\right)(p(0)-\bar{p}) \lambda_{2} e^{\lambda_{2} t}+\delta \bar{p}}{e^{-r \omega}}$ so $\tau(t)=\frac{\left(\lambda_{2}+\delta\right)(p(0)-\bar{p}) \lambda_{2} e^{\lambda_{2} t}+\delta \bar{p}}{e^{-r \omega}}$. Differentiating wrt to $t$ gives $\dot{\tau}(t)=\frac{\left(\lambda_{2}+\delta\right)(p(0)-\bar{p})\left(\lambda_{2}\right)^{2} e^{\lambda_{2} t}}{e^{-r \omega}}>0$ so $\ddot{\tau}(t)=$ $\frac{\left(\lambda_{2}+\delta\right)(p(0)-\bar{p})\left(\lambda_{2}\right)^{3} e^{\lambda_{2} t^{e^{-r \omega}}}}{e^{-r \omega}}<0$ which immediately implies $\frac{\tau(t+\omega)}{\tau(t)}$ is decreasing in $t$, so $\frac{b(t)}{\tau(t)}$ is increasing in $t$. Thus as the system converges to the saddle point equilibrium along the stable branch the share of taxes corruptly appropriated by the government increases monotonically.

\subsection{Public Corruption Relative to Private Consumption.}

We may also be interested in the time path of government consumption/corruption compared to private consumption or

$$
\frac{b(t)}{c(t)}=\frac{\left(\lambda_{2}+\delta\right)(p(0)-\bar{p}) \lambda_{2} e^{\lambda_{2} t}\left[e^{r \omega}-e^{\lambda_{2} \omega}\right]+\delta \bar{p}\left(e^{r \omega}-1\right)}{\bar{c}-\left(\frac{v+\lambda_{2}}{2 w}\right)(p(0)-\bar{p}) e^{\lambda_{2} t}} .
$$

Since both $b(t)$ and $c(t)$ are increasing at decreasing rates this requires we differentiate wrt $t$ to get

$$
\begin{aligned}
\left(\frac{\dot{b(t)}}{c(t)}\right)= & \frac{\left(\lambda_{2}+\delta\right)(p(0)-\bar{p})\left(\lambda_{2}\right)^{2} e^{\lambda_{2} t}\left[e^{r \omega}-e^{\lambda_{2} \omega}\right]\left[\bar{c}-\left(\frac{v+\lambda_{2}}{w}\right)(p(0)-\bar{p}) e^{\lambda_{2} t}\right]}{\left[\bar{c}-\left(\frac{v+\lambda_{2}}{2 w}\right)(p(0)-\bar{p}) e^{\lambda_{2} t}\right]^{2}} \\
& +\frac{\lambda_{2}\left(\frac{v+\lambda_{2}}{2 w}\right)(p(0)-\bar{p}) e^{\lambda_{2} t}\left[\left(\lambda_{2}+\delta\right)(p(0)-\bar{p}) \lambda_{2} e^{\lambda_{2} t}\left[e^{r \omega}-e^{\lambda_{2} \omega}\right]+\delta \bar{p}\left(e^{r \omega}-1\right)\right]}{\left[\bar{c}-\left(\frac{v+\lambda_{2}}{2 w}\right)(p(0)-\bar{p}) e^{\lambda_{2} t}\right]^{2}}
\end{aligned}
$$

as $t \rightarrow \infty$ and using (20) and (21) we get

$$
\left(\frac{\dot{b(t)}}{c(t)}\right)=\frac{\delta \bar{p}\left(e^{r \omega}-1\right)}{\bar{c}^{2}}=\frac{\delta\left(e^{r \omega}\right)^{\frac{2 \beta-1}{1-\beta}}\left(e^{r \omega}-1\right)}{\left[\left(\frac{\delta+r}{\beta}\right)-\delta\right]}>0 .
$$

The corrupt government gets relatively larger. Corruption and household sector consumption grow as the economy approaches the steady state from below, but corruption grows faster.

\subsection{Theory and the Empirical Evidence.}

For the reader cognizant of the empirical literature it might seem that the theoretical prediction of this section are inconsistent with the evidence as discussed by Mauro (op. cit), Ehrlich and Lui (op. cit.) and Lambsdorff (op. cit.). The opposite is true. The empirical literature reports a negative relationship between the growth rate of output and the level of corruption, and does not investigate the time path of the ratio of these variables. If we derive (appendix) the relationship between the rate of growth of output, $\frac{\dot{y}(t) \text {, }}{y(t)}$ and the level of corruption, $b(t)$, along the saddle path we obtain

$$
\frac{\dot{y}(t)}{y(t)}=\left[\frac{\beta}{(p(0)-\bar{p}) e^{\lambda_{2} t}+\bar{p}}\right]\left[\frac{b(t)-\delta \bar{p}\left(e^{r \omega}-1\right)}{\left(\lambda_{2}+\delta\right)\left(e^{r \omega}-e^{\lambda_{2} \omega}\right)}\right] .
$$


This is of the form $\frac{\dot{y}(t)}{y(t)}=A(t)-a(t) b(t)$, with $A(t)>0$, and $a(t)>0$ as in the empirical literature. Higher levels of corruption are associated with lower level of output growth, however it should be stressed again that this relationship is not causal.

In a sense this result is obvious. For any Ramsey type model more mature economies closer to their steady states, will, ceteris paribus, have higher output and slower growth rates. Any model in this class that also displays the property that corruption is non-decreasing in output will yield predictions similar to (40). While it might be then concluded that this provides further support for the argument that the neoclassical model is an adequate explanation of the growth process. To us this also suggests that the common empirical model might productively be revized to include measures of relative corruption such as the ratio of corruption to output. Otherwise empirical discrimination between competing theoretical models might prove difficult.

\section{The Comparative Dynamics of Corruption and the Effects of Trans- parency.}

To obtain insight into the comparative dynamics of the model it has proven necessary to result to numerical methods. Below is a sample of the numerical results obtained. All other parameter values for which numerical solutions were obtained produced qualitatively similar conclusions.

\begin{tabular}{ccccccc}
\hline & \multicolumn{5}{c}{ Time Interval $t$} \\
\hline & 1 & 0.00105221 & 0.00652015 & 0.0079946 & 0.0079946 & 0.0079946 \\
& 2 & 0.0102911 & 0.00817894 & 0.0101997 & 0.0101997 & 0.0101997 \\
Transparency & 4 & 0.0142925 & 0.0195653 & 0.0216999 & 0.0216999 & 0.0216999 \\
$\omega$ & 8 & 0.0291157 & 0.0353097 & 0.0491617 & 0.049286 & 0.049286 \\
& 16 & 0.129243 & 0.129227 & 0.129115 & 0.128937 & 0.128937 \\
\hline \multicolumn{6}{c}{ Share of Corruption in Output $\frac{b(t)}{y(t)} \cdot{ }^{13}$} \\
\hline
\end{tabular}

As the table indicates the share of corruption in total output along the stable branch is monotonically increasing in the length of the production lag, or, alternatively expressed it is decreasing in the level of fiscal transparency. The results do seem to emphasize the importance of fiscal transparency. For a unit transparency interval the share of corruption in output falls in the seemingly trivial range of one tenth to seven tenth of one percent. At the other extreme for a transparency interval 16 times larger the share of corruption in output rises to approximately $13 \%$ which represents a 130 fold increase at the start of the path $t=0$ and a 16 fold increase as $t=10^{6}$ (which is obviously close to the steady state). This suggests that a lack of fiscal transparency has particularly severe effects for economies in the early stages of growth.

\section{Extensions.}

\subsection{Bolt Holes.}

When a corrupt regime is removed its leaders typically seek refuge outside the country. For example Idi Amin now resides in Saudi Arabia, while Ferdinand Marcos and his wife Imelda fled to Hawaii in 1986. The value of this outside option effects the behavior of the government when in power. If we write the flow value of this outside option as $a(t)$ then the corruption irreducability constraint must be modified to appear as

$$
\int_{j=t}^{\infty} b(j) e^{-r j} d j=\int_{j=t}^{t+\omega} \tau(j) e^{-r j} d j+\int_{j=t+\omega}^{\infty} a(j) e^{-r j} d j \forall t
$$

Using the same techniques as before then the dynamic system become

$$
\dot{p}(t)=\left[p(t)^{\beta}-c(t)-a(t-\omega)\right] e^{-r \omega}-\delta p(t),
$$

\footnotetext{
${ }^{13}$ For the results reported we used the parameter values $r=\delta=0.06, \theta=\beta=0.5$. The results reported for $\omega=16$ are not anomolous as this yields an initial public capital stock above the steady state level.
} 
and

$$
\dot{c}(t)=\left(\frac{1}{\theta-1}\right)\left[\delta-\beta p(t)^{\beta-1} e^{-r \omega}+r\right][c(t)-1] .
$$

Hence the stationaries are now

$$
c(t)=p(t)^{\beta}-\frac{\delta p(t)}{e^{-r \omega}}-a(t-\omega)
$$

and

$$
c(t)=1 \text { or } p(t)=\left(\frac{\beta e^{-r \omega}}{\delta+r}\right)^{\frac{1}{1-\beta}} .
$$

Representing this information on a phase diagram we see that an increase in the outside option shifts the $\dot{p}(t)=0$ stationary as indicated in figure 3

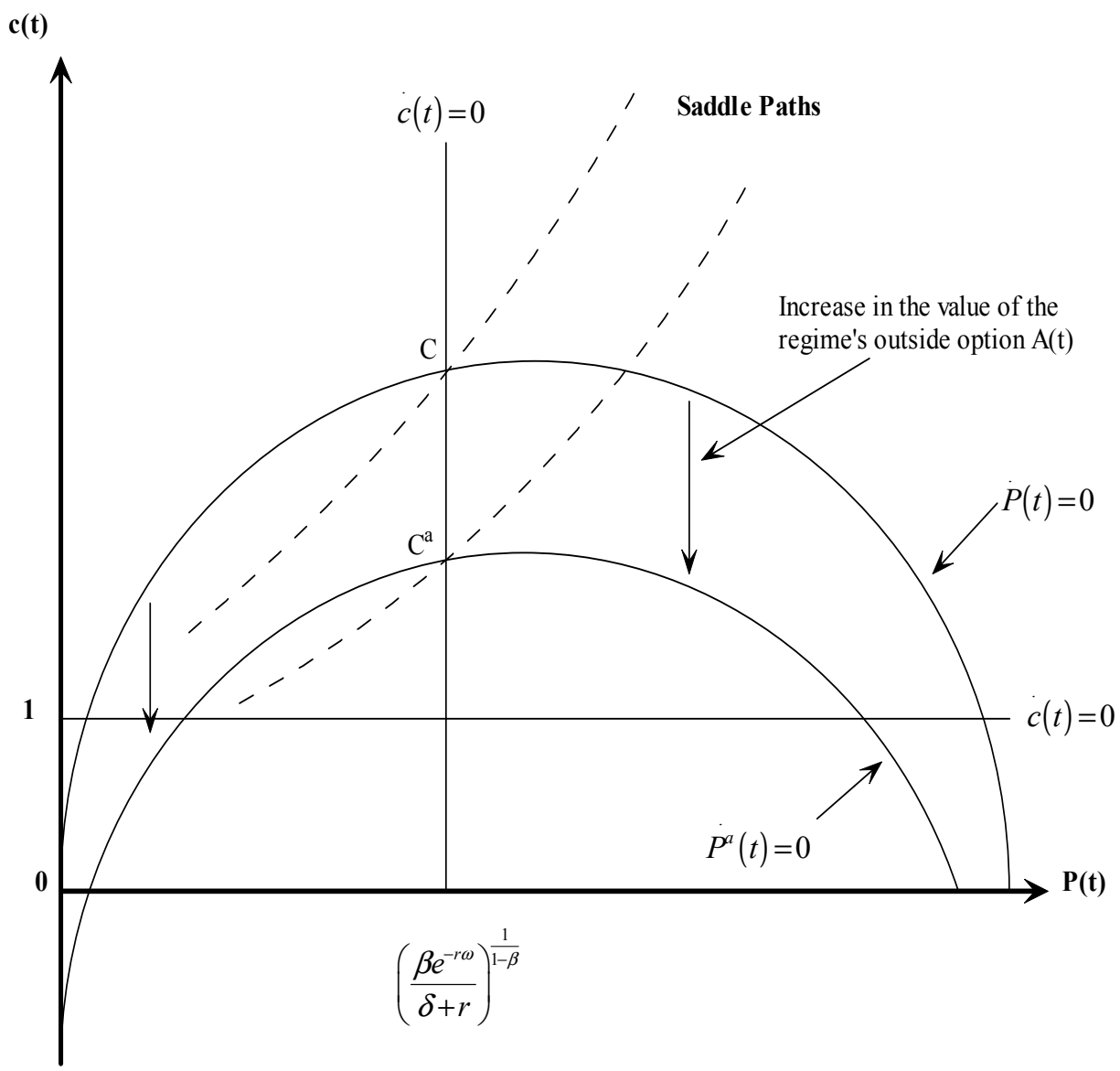

Figure 3: Changes in the Outside Option.

An increases in the value of the regimes outside option shifts the $\dot{p}(t)=0$ downwards lowering the level of consumption both at the steady state and along the saddle path for each level of the public capital stock.

Our measures of steady state corruption may now be rewritten as

$$
\begin{gathered}
\frac{\bar{b}}{\bar{y}}=\left(1-e^{-r \omega}\right)\left(\frac{\delta \beta}{\delta+r}\right)+a(t-\omega)\left(\frac{\beta e^{-r \omega}}{\delta+r}\right)^{-\left(\frac{\beta}{1-\beta}\right)}, \\
\frac{\bar{b}}{\bar{\tau}}=\frac{\left(e^{r \omega}-1\right) \delta\left(\frac{\beta e^{-r \omega}}{\delta+r}\right)^{\frac{1}{1-\beta}}+a(t-\omega)}{\delta e^{r \omega}\left(\frac{\beta e^{-r \omega}}{\delta+r}\right)^{\frac{1}{1-\beta}}+a(t-\omega)},
\end{gathered}
$$


and

$$
\frac{\bar{b}}{\bar{c}}=\frac{\left(e^{r \omega}-1\right) \delta\left(\frac{\beta e^{-r \omega}}{\delta+r}\right)^{\frac{1}{1-\beta}}+a(t-\omega)}{\left[\left(\frac{\beta}{\delta+r}\right)^{\frac{\beta}{1-\beta}}-\delta\left(\frac{\beta}{\delta+r}\right)^{\frac{1}{1-\beta}}\right]\left(e^{-r \omega}\right)^{\frac{\beta}{1-\beta}}-a(t-\omega)} .
$$

Clearly increases in the value of the outside option raise each of our measures of corruption ${ }^{14}$, that is

$$
\frac{d\left(\frac{\bar{b}}{\bar{y}}\right)}{d a(t-\omega)}>0, \frac{d\left(\frac{\bar{b}}{\bar{\tau}}\right)}{d a(t-\omega)}>0, \text { and } \frac{d\left(\frac{\bar{b}}{\bar{c}}\right)}{d a(t-\omega)}>0 .
$$

This has an immediate implication. It suggests that it is not a good idea to try to eliminate a corrupt regime by offering its members an attractive outside option. This will simply allow them to divert more of the economics resources to themselves at the expense of private sector consumption. It also tells us that corruption may have international spillovers. If we associate higher values of $a(t)$ with more corrupt potential "hosts", then each regime will be more corrupt if it has a similar regime to shelter it in the advent of its being deposed.

\subsection{Impatience and Political Insecurity.}

It has frequently been proposed that the public and private sectors could have different discount rates, and as we shall see this has interesting implications for our analysis ${ }^{15}$. There are several interpretations that can be placed on this difference. One interpretation, from the public finance literature, is that the private sector are to some extent myopic and thus effectively over-discount the future ${ }^{16}$. In game theory higher discount rates are sometimes interpreted as representing a higher probability that the game will terminate in any given period. Different discount rates then represent different probabilities that the game will end for each player. ${ }^{17}$ Alternatively, and most simply, different discount rates may arise because of different rates of time preference. Since we assume that both the government and private sector are fully forward looking we concentrate on these latter two interpretations. To illustrate the possibilities it is necessary to modify the model slightly.

Writing the private sector discount rate as $\eta$ we can easily show that the solution for the models dynamics obey

$$
\dot{p}(t)=\left[p(t)^{\beta}-c(t)\right] e^{-r \omega}-\delta p(t),
$$

and

$$
\dot{c}(t)=\left(\frac{1}{\theta-1}\right)\left[\delta-\beta p(t)^{\beta-1} e^{-r \omega}+\eta\right][c(t)-1] .
$$

The steady states are the solutions to the stationaries

$$
c(t)=p(t)^{\beta}-\frac{\delta p(t)}{e^{-r \omega}}
$$

and

$$
c(t)=1 \text { or } p(t)=\left(\frac{\beta e^{-r \omega}}{\delta+\eta}\right)^{\frac{1}{1-\beta}} .
$$

With these modifications greater impatience on the part of the private sector involves a greater value of $\eta$, while greater impatience by the government is captured by higher values of $r$. The implications of different levels of impatience for the model are captured in figures 4 and 5.

\footnotetext{
${ }^{14}$ Only $\frac{d\left(\frac{\bar{b}}{\tau}\right)}{d a(t-\omega)}>0$ may not be immediately obvious, but recall that $\bar{b} \leq \bar{\tau}$ at $a(t-\omega)=0$, or the government would be stealing more than all the tax revenues available for theft.

${ }^{15}$ We thank Toke Aidt for suggesting this to us.

${ }^{16}$ See for example Rosen [18].

${ }^{17}$ Games in which one player may play against a sequence of opponents and thus the players have different time horizons are called recurring games.
} 


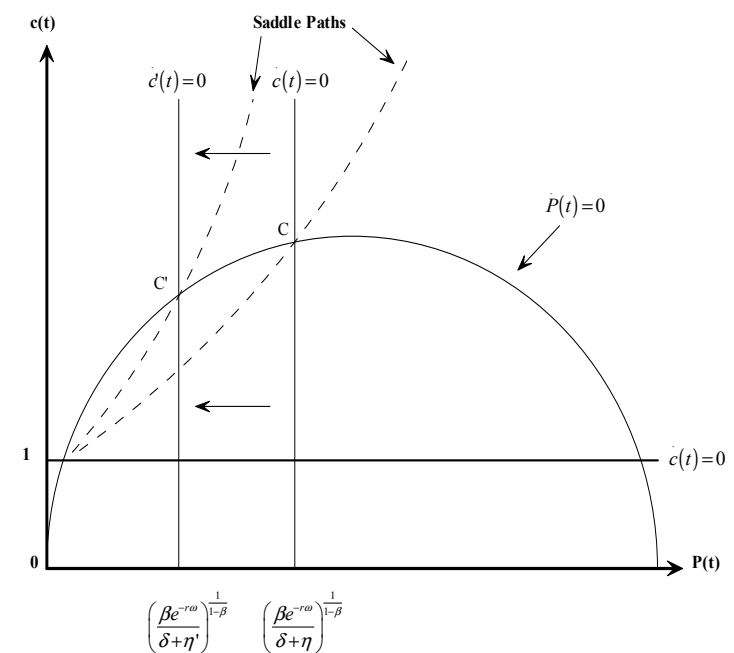

Figure 4: Private Sector Impatience.

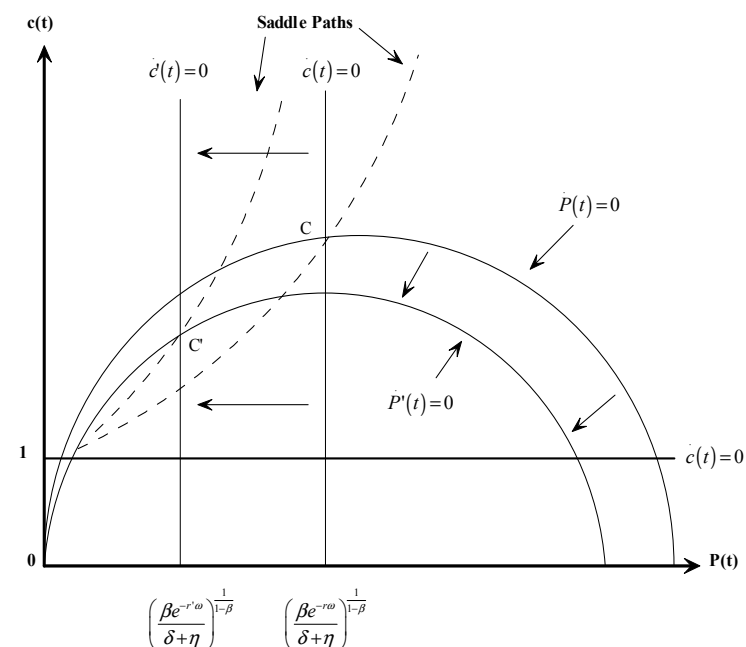

Figure 5: Government Impatience.

Greater impatience by the private sector, $\eta^{\prime}>\eta$, shifts the vertical $\dot{c}(t)=0$ stationary leftwards as in figure 4. We see immediately that the steady state levels of consumption, the public capital stock, and hence output fall. This reflects the response of the government to different private sector preferences. For the private sector an increase in the discount rate implies a decrease in the sacrifice they are willing to make today to receive a dollar in the future. Hence a competitive government recognizes that and cuts taxes and the rate of public capital accumulation as shown.

Greater impatience on the part of the government, as illustrated in figure 5 , both shifts the vertical $\dot{c}(t)=0$ stationary leftwards and rotates the $\dot{p}(t)=0$ stationary clockwise around the origin. Again the steady state levels of consumption, the public capital stock and output fall. Here the story is more complex. Greater impatience by the government means that they are less willing to forgo current for future corruption payments. Stealing today becomes more attractive relative to stealing in the future, so there is less incentive to invest today to supply future opportunities for corruption.

With the distinction between public and government discount rates the steady state level of absolute corruption can be rewritten as

$$
\bar{b}=\delta\left(\frac{\beta}{\delta+\eta}\right)^{\frac{1}{1-\beta}} e^{-\frac{r \omega}{1-\beta}}\left(e^{\beta}-1\right) .
$$

While the steady state measures of relative corruption become

$$
\frac{\bar{b}}{\bar{y}}=\left(1-e^{-r \omega}\right)\left(\frac{\delta \beta}{\delta+\eta}\right), \quad \frac{\bar{b}}{\bar{\tau}}=\left(1-e^{-r \omega}\right), \quad \frac{\bar{b}}{\bar{c}}=\frac{\left(1-e^{-r \omega}\right) \delta}{\frac{\delta+\eta}{\beta}-\delta} .
$$

So changes in the levels of public or government impatience clearly imply

$$
\frac{d \bar{b}}{d r}<0, \frac{d \bar{b}}{d \eta}<0
$$

Greater impatience by either the government or private sector reduces the absolute level of corruption. Greater impatience leads to lower levels of investment generally, hence lower steady state levels of output and taxes. That is there is absolutely less to steal so corruption falls.

For relative corruption the effects of impatience depend on which discount rats in question, we have

$$
\frac{d\left(\frac{\bar{b}}{\bar{y}}\right)}{d r}>0, \frac{d\left(\frac{\bar{b}}{\bar{\tau}}\right)}{d r}>0, \frac{d\left(\frac{\bar{b}}{\bar{c}}\right)}{d r}>0, \frac{d\left(\frac{\bar{b}}{\bar{y}}\right)}{d \eta}<0, \frac{d\left(\frac{\bar{b}}{\bar{\tau}}\right)}{d \eta}=0, \quad \text { and } \frac{d\left(\frac{\bar{b}}{\bar{c}}\right)}{d \eta}<0 .
$$

When considering relative corruption there is an interesting asymmetry. Whereas an increase in either the discount rate for the government or the private sector reduces investment and output, the former increases our measures of 
corruption while the latter reduces them. That is the relatively more impatient is the government, the greater are our measures of corruption. In terms of the level of output and the share of corruption in the economy the worst scenario is an impatient government operating a highly non-transparent regime. If we apply the interpretation that a higher discount rate for the government proxies for shorter time horizon, then this might perhaps represent the level of political insecurity of the regime. The implication is that politically insecure regimes tend to invest and produce less, and appropriate relatively more of what is produced. For a given level of transparency corrupt secure regimes are better than insecure ones.

\subsection{Corruption and Transition.}

One particular episode onto which our model may shed some light is the transition experience of the countries that previously comprised the Soviet Union. In a recent survey paper Campos and Coricelli [7] argue that prior to transition the Soviet economies had been subject to excessive levels of public capital accumulation. After the break up of the USSR the experience of these countries followed a set of stylized facts. Most particularly they experienced a rapid decline in both output and capital stock. The capital stock decline was not limited to physical capital but also included a decline in human capital accumulation. How this process might be represented using our model is illustrated in figure 3 .

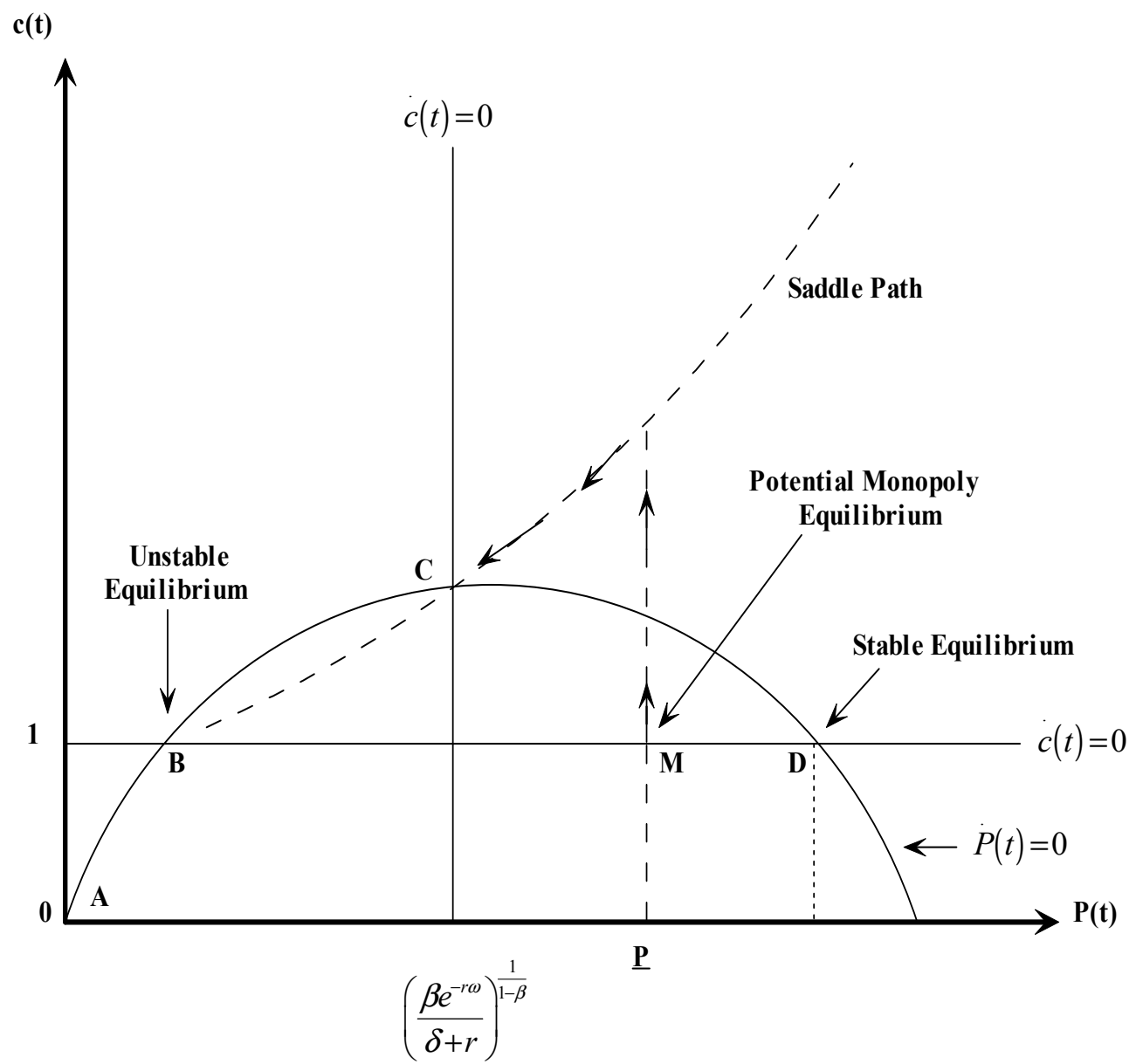

Figure 5: Transition Economy Dynamics.

The economy is initially at the monopoly equilibrium $M$ characterized by an excessive level of the public capital stock $\underline{P}>\left(\frac{\beta e^{-r \omega}}{\delta+r}\right)^{\frac{1}{1-\beta}}$. The change in political regime is accompanied by a jump in consumption as the 
economy moves onto the saddle path at $\underline{P}$. Given an initial public capital stock and the discontinuous increase in consumption it follows that initially corruption must discontinuously fall. Subsequently both consumption and the capital stock fall as the system converges to equilibrium along the saddle path. As our previous results indicate the fall in consumption and public capital will be accompanied by falling levels of absolute corruption, as shown in figure 4 .

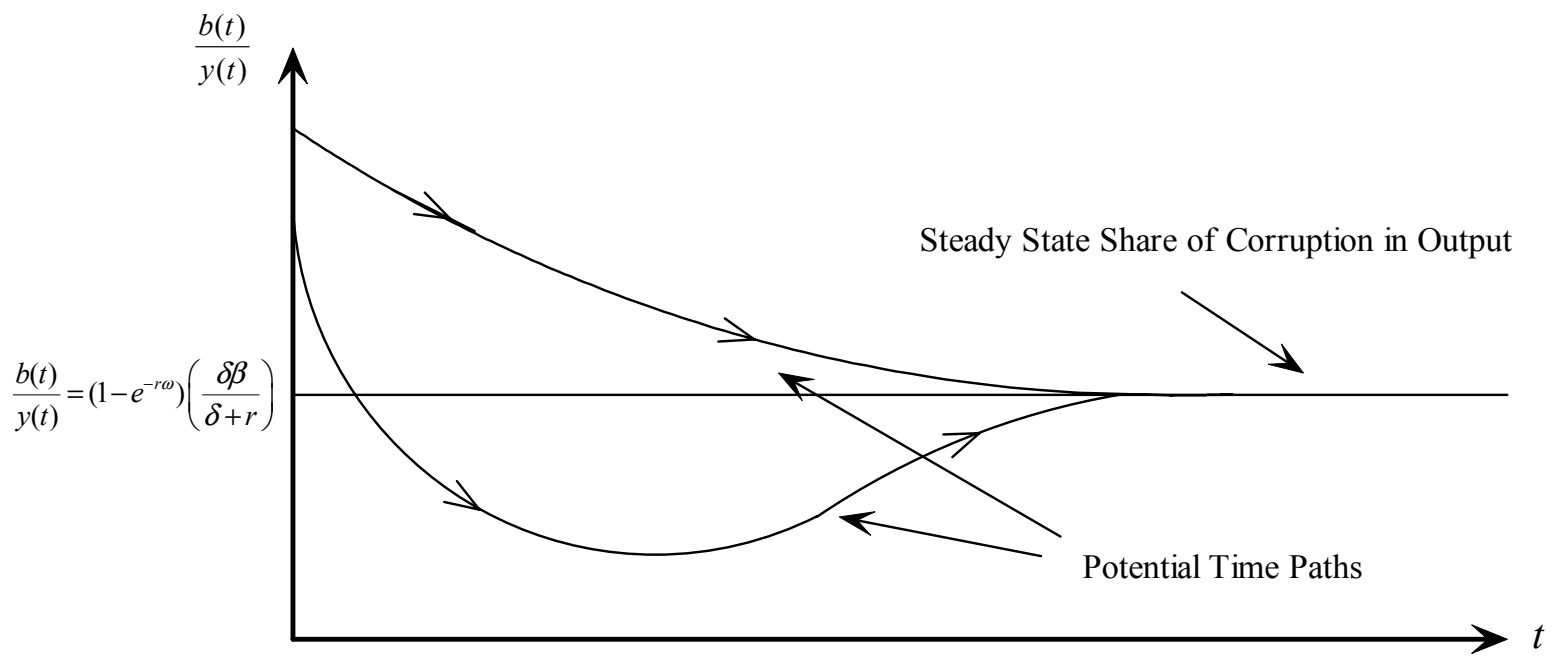

Figure 6: Relative Corruption after Transition.

Again there is the possibility of corruption initially overreacting by undershooting its steady state level, before rising back to the steady state. Notice however that overall government corruption must unambiguously decline from its initial monopoly equilibrium level.

\section{Conclusions.}

We have developed a simple theoretically appealing model of the relationship between corruption and the levels and growth rates of output. In our model corruption is endogenous and depends on deep economic parameters including the degree of transparency of the fiscal system. All economic agents, government, the bureaucracy and the private sector are rational selfish maximizers. The government exists for a purpose, to provide an essential public input good into the private sector production technology; hence here corruption problems cannot be eliminated by eliminating the government. Also theoretically appealing is the tractability of our analysis. Despite having to deal with the technical problems associated with delayed controls, we are able to obtain closed form solutions to the government's dynamic optimization problem. We are thus able to obtain predictions concerning comparative statics of the steady state, the economy's transition dynamics, and the comparative dynamic effects of changes in the models parameters.

The predictions of our model correspond well to several key empirical facts and also throw up some new questions for investigation. The key finding of the empirical growth literature is that there is a negative relationship between economic growth and the level of corruption. In our analysis we see that as the system converges to the steady state along the saddle path there is a negative relationship between the rate of growth of output and the level of corruption. However, this relationship is not causal, and depends on the models parameters most particularly the degree of transparency of the fiscal system. Simulations of the growth path also reveal that lower levels of fiscal transparency translate into a higher corruption-output ratios at every point in time. A second empirical literature looks at differences in levels of output per worker across countries and concludes that the quality of economic institutions is a key causal factor ${ }^{18}$. One interpretation of our transparency variable is that it captures the quality of economic institutions. The steady state results that output is increasing in fiscal transparency, and that the share of corruption in output is decreasing in fiscal transparency fit nicely with this empirical fact.

\footnotetext{
${ }^{18}$ Plus distance from the tropics and use of English.
} 
Of perhaps lesser significance, but still encouraging, are the models predictions concerning the effects of the depreciation rate and interest rate on our measures of corruption. Higher depreciation rates may be thought of as reflecting inferior quality pubic investments, a feature reported to occur in highly corrupt developing economies. In our analysis a rise in the depreciation rate results in lower steady state output levels and higher levels of corruption relative to output and relative to private sector consumption. It has also been suggested that the variability in corruption is a deterrent to economic development. In as much as the interest rate may be assumed to include a risk premium, our model accords well with this possibility.

We also consider two extensions to our base model. First; we allow the government to have an outside option, a "bolt hole" to which they may run if they default on their promises to the household sector and are deposed. We find that a form of moral hazard arises. Should a third party offer the corrupt government an attractive outside option, essentially insurance, then they respond by extracting higher corruption rents and doing greater damage to their domestic economy. Second, we allow for different rates of time preference between the government and household sectors. We find that higher relative rates of government time preference, greater impatience, lead to lower steady state levels of output and household sector consumption, and higher levels of relative corruption.

In the context of explaining the experience of transition economies we find that if there is initial excessive investment in public capital, then the time path subsequently followed by the model economy displays several of the features displayed by members of the former Soviet-bloc. In the immediate post transition period consumption initially jump up, but then declines gradually as the level of public capital and output converge to the steady state from above.

While we believe our theoretical structure does a surprisingly good job at explaining some of the key features of growth in economies suffering from corruption, it is clearly only a first step only. There are several directions in which we expect future work will extend our analysis. The introduction of private capital would seem to be the most critical. The empirical literature reports, a negative relationship between corruption and private capital accumulation. A fact that we are currently unable to address. There is also considerable interest in how corruption effects international capital flows especially foreign direct investment. Clearly it would be interesting to embed our model in an open economy framework and address these issues. 


\section{Appendix.}

\subsection{Proof that the Solution Technique Satisfies the Integral Constraint, Equation (9).}

Since the corruption constraint $\int_{j=t}^{\infty} b(j) e^{-r j} d j=\int_{j=t}^{t+\omega} \tau(j) e^{-r j} d j$ holds for all $t$, it follows that the time derivative of this constraint $-b(t) e^{-r t}=\tau(t+\omega) e^{-r(t+\omega)}-\tau(t) e^{-r t}$ does also. So to check that the solution satisfies the integral constraint consider the derivative constraint at the steady state or $\bar{b}=\left(1-e^{-r \omega}\right) \bar{\tau}$. Substituting this back into the integral constraint yields $\left(1-e^{-r \omega}\right) \bar{\tau} \int_{j=t}^{\infty} e^{-r j} d j=\bar{\tau} \int_{j=t}^{t+\omega} e^{-r j} d j$. Performing the integration immediately reveals the integral constraint is satisfied and thus the solution technique valid.

\subsection{Solution to the Dynamic Optimization Problem.}

The current value Hamiltonian can be written as in (15)

$$
\operatorname{Max} H=[c(t)-1]^{\theta} e^{-r t}+\xi(t)\left[p(t)^{\beta} e^{-r \omega}-c(t) e^{-r \omega}-\delta p(t)\right]
$$

The first order condition is

$$
\theta[c(t)-1]^{\theta-1} e^{-r t}-\xi(t) e^{-r \omega}=0
$$

and the equations of motion are

$$
\dot{\xi(t)}=-\frac{\partial H}{\partial p(t)}=-\xi(t) \beta p(t)^{\beta-1} e^{-r \omega}+\xi(t) \delta
$$

and

$$
\dot{p}(t)=p(t)^{\beta} e^{-r \omega}-c(t) e^{-r \omega}-\delta p(t)
$$

Before we begin our analysis it is useful to transform the $\dot{\xi(t)}$ equation into a $c(t)$ equation. Rewriting the first order condition gives

$$
\xi(t)=\theta[c(t)-1]^{\theta-1} e^{-r(t-\omega)}
$$

differentiating this expression wrt to time gives us

$$
\dot{\xi}(t)=\theta(\theta-1)[c(t)-1]^{\theta-2} c(t) e^{-r(t-\omega)}-\theta[c(t)-1]^{\theta-1} r e^{-r(t-\omega)}
$$

substituting into the $\dot{\xi}$ differential equation gives us

$$
\theta(\theta-1)[c(t)-1]^{\theta-2} c \dot{c}(t) e^{-r(t-\omega)}-\theta[c(t)-1]^{\theta-1} r e^{-r(t-\omega)}=\left[\delta-\beta p(t)^{\beta-1} e^{-r \omega}\right] \theta[c(t)-1]^{\theta-1} e^{-r(t-\omega)}
$$

or

$$
(\theta-1) \dot{c(t)}-[c(t)-1] r=\left[\delta-\beta p(t)^{\beta-1} e^{-r \omega}\right][c(t)-1]
$$

which can be simplified and rearranged to give

$$
\dot{c}(t)=\left(\frac{1}{\theta-1}\right)\left[\delta-\beta p(t)^{\beta-1} e^{-r \omega}+r\right][c(t)-1]
$$

hence the dynamic system is

$$
\begin{aligned}
& \dot{p}(t)=p(t)^{\beta} e^{-r \omega}-c(t) e^{-r \omega}-\delta p(t) \\
& \dot{c}(t)=\left(\frac{1}{\theta-1}\right)\left[\delta-\beta p(t)^{\beta-1} e^{-r \omega}+r\right][c(t)-1]
\end{aligned}
$$

As given in equations (16) and (17). 


\subsection{Properties of the Phase Diagram.}

Equating (16) and (17) to zero the stationaries of the phase diagram are given by

$$
\begin{aligned}
& c(t)=p(t)^{\beta}-\frac{\delta p(t)}{e^{-r \omega}} \\
& c(t)=1 \text { or } p(t)=\left(\frac{\beta e^{-r \omega}}{\delta+r}\right)^{\frac{1}{1-\beta}} .
\end{aligned}
$$

Differentiating (18) and (19) the slopes of the stationaries are

$$
\begin{aligned}
& \left.\frac{d c(t)}{d p(t)}\right|_{\dot{p}(t)=0}=\beta p(t)^{\beta-1}-\frac{\delta}{e^{-r \omega}} \\
& \left.\frac{d c(t)}{d p(t)}\right|_{\dot{c}(t)=0}=0 \text { or } \infty
\end{aligned}
$$

and the $c(t)$ intercepts are given by

$$
\begin{gathered}
\left.c(t)\right|_{\dot{p}(t)=0}=0 \\
\left.c(t)\right|_{\dot{c}(t)=0}=1
\end{gathered}
$$

thus the stationaries are as drawn in figure 1.

The streamlines in the diagram follow from

$$
\frac{\partial \dot{p}(t)}{\partial c(t)}=-e^{-r \omega}<0
$$

and

$$
\frac{\partial \dot{c}(t)}{\partial p(t)}=-\beta(\beta-1)\left(\frac{1}{\theta-1}\right) p(t)^{\beta-2} e^{-r \omega}[c(t)-1] \gtreqless 0 \text { as } c(t) \gtreqless 1 .
$$

\subsection{The Linearized System and the Linear Approximation to the Saddle Path.}

To gain an approximation to the stable arm we linearize the dynamic system around the saddle path stable equilibrium to obtain

$$
\begin{gathered}
\dot{p}(t)-\left[\beta \bar{p}^{\beta-1} e^{-r \omega}-\delta\right][p(t)-\bar{p}]+\left[e^{-r \omega}\right][c(t)-\bar{c}]=0 \\
\dot{c}(t)+\left[\left(\frac{1}{\theta-1}\right)\left(\beta(\beta-1) \bar{p}^{\beta-2} e^{-r \omega}\right)(\bar{c}-1)\right][p(t)-\bar{p}]-\left[\left(\frac{1}{\theta-1}\right)\left(\delta-\beta \bar{p}^{\beta-1} e^{-r \omega}+r\right)\right][c(t)-\bar{c}]=0
\end{gathered}
$$

or

$$
\begin{gathered}
\dot{p}(t)-\left(\beta \bar{p}^{\beta-1} e^{-r \omega}-\delta\right) p(t)+e^{-r \omega} c(t)+\left(\beta \bar{p}^{\beta-1} e^{-r \omega}-\delta\right) \bar{p}-e^{-r \omega} \bar{c}=0 \\
\dot{c}(t)+\left(\frac{1}{\theta-1}\right)\left(\beta(\beta-1) \bar{p}^{\beta-2} e^{-r \omega}\right)(\bar{c}-1) p(t)-\left(\frac{1}{\theta-1}\right)\left(\delta-\beta \bar{p}^{\beta-1} e^{-r \omega}+r\right) c(t) \\
-\left(\frac{1}{\theta-1}\right)\left(\beta(\beta-1) \bar{p}^{\beta-2} e^{-r \omega}\right)(\bar{c}-1) \bar{p}+\left(\frac{1}{\theta-1}\right)\left(\delta-\beta \bar{p}^{\beta-1} e^{-r \omega}+r\right) \bar{c}=0
\end{gathered}
$$

where the saddle path equilibrium solutions are

$$
\begin{aligned}
& \bar{c}=\left[\left(\frac{\beta}{\delta+r}\right)^{\frac{\beta}{1-\beta}}-\delta\left(\frac{\beta}{\delta+r}\right)^{\frac{1}{1-\beta}}\right]\left(e^{-r \omega}\right)^{\frac{\beta}{1-\beta}} \\
& \bar{p}=\left(\frac{\beta e^{-r \omega}}{\delta+r}\right)^{\frac{1}{1-\beta}}
\end{aligned}
$$

and also constitute the particular integrals.

let 
1. $v=-\beta \bar{p}^{\beta-1} e^{-r \omega}-\delta$

2. $w=e^{-r \omega}$

3. $a=\left(\beta \bar{p}^{\beta-1} e^{-r \omega}-\delta\right) \bar{p}-e^{-r \omega} \bar{c}$

4. $x=\left(\frac{1}{\theta-1}\right)\left(\beta(\beta-1) \bar{p}^{\beta-2} e^{-r \omega}\right)(\bar{c}-1)$

5. $z=-\left(\frac{1}{\theta-1}\right)\left(\delta-\beta \bar{p}^{\beta-1} e^{-r \omega}+r\right)$

6. $b=-\left(\frac{1}{\theta-1}\right)\left(\beta(\beta-1) \bar{p}^{\beta-2} e^{-r \omega}\right)(\bar{c}-1) \bar{p}+\left(\frac{1}{\theta-1}\right)\left(\delta-\beta \bar{p}^{\beta-1} e^{-r \omega}+r\right) \bar{c}$

or simplifying

1. $v=-r$

2. $w=e^{-r \omega}$

3. $a=\left[(\delta+r)\left(\frac{\beta}{\delta+r}\right)^{\frac{1}{1-\beta}}-\left(\frac{\beta}{\delta+r}\right)^{\frac{\beta}{1-\beta}}\right]\left(e^{-r \omega}\right)^{\frac{1}{1-\beta}}$

4. $x=\left(\frac{1}{\theta-1}\right)\left(\beta(\beta-1)\left(\frac{\beta}{\delta+r}\right)^{\frac{\beta-2}{1-\beta}}\left(e^{-r \omega}\right)^{-\frac{1}{1-\beta}}\right)(\bar{c}-1)$

5. $z=0$

6. $b=-\left(\frac{1}{\theta-1}\right)(\beta-1)(\delta+r)(\bar{c}-1)$

Our dynamic system is of the form

$$
\begin{aligned}
\dot{p}(t)+v p(t)+w c(t) & =a \\
\dot{c}(t)+x p(t)+z c(t) & =b
\end{aligned}
$$

In matrix form we get

$$
\begin{gathered}
J u+M q=g \\
J=\left[\begin{array}{ll}
1 & 0 \\
0 & 1
\end{array}\right], u=\left[\begin{array}{c}
\dot{p}(t) \\
\dot{c}(t)
\end{array}\right], M=\left[\begin{array}{cc}
v & w \\
x & 0
\end{array}\right], q=\left[\begin{array}{c}
p(t) \\
c(t)
\end{array}\right], g=\left[\begin{array}{c}
a \\
b
\end{array}\right]
\end{gathered}
$$

The particular integrals are just our solutions for the saddle path equilibrium

$$
\{\bar{p}, \bar{c}\}
$$

The complementary functions may be derived as follows

Try the trial solution

$$
u=\left[\begin{array}{c}
m \\
n
\end{array}\right] \lambda e^{\lambda t}, q=\left[\begin{array}{c}
m \\
n
\end{array}\right] e^{\lambda t}
$$

The reduced dynamic system is

$$
J u+M q=0
$$

hence

$$
J\left[\begin{array}{c}
m \\
n
\end{array}\right] \lambda e^{\lambda t}+M\left[\begin{array}{c}
m \\
n
\end{array}\right] e^{\lambda t}=0
$$

or dividing by $e^{\lambda t}$

$$
(\lambda J+M)\left[\begin{array}{c}
m \\
n
\end{array}\right]=0
$$


the characteristic equation is

$$
|\lambda J+M|=\left|\begin{array}{cc}
v+\lambda & w \\
x & \lambda
\end{array}\right|=\lambda^{2}+\lambda v-x w=0
$$

hence the characteristic roots are defined as

$$
\begin{aligned}
& \lambda_{1}=\frac{-v+\sqrt{v^{2}+4 x w}}{2} \\
& \lambda_{2}=\frac{-v-\sqrt{v^{2}+4 x w}}{2}
\end{aligned}
$$

we know the equilibrium is a saddle path with $\lambda_{1}>0>\lambda_{2}$, where the negative root is associated with the stable branch. Reinserting the roots gives

$$
\begin{gathered}
(\lambda J+M)\left[\begin{array}{c}
m_{1} \\
n_{1}
\end{array}\right]=\left[\lambda_{1}\left[\begin{array}{ll}
1 & 0 \\
0 & 1
\end{array}\right]+\left[\begin{array}{ll}
v & w \\
x & 0
\end{array}\right]\right]\left[\begin{array}{l}
m_{1} \\
n_{1}
\end{array}\right]=0 \\
{\left[\begin{array}{cc}
v+\lambda_{1} & w \\
x & \lambda_{1}
\end{array}\right]\left[\begin{array}{c}
m_{1} \\
n_{1}
\end{array}\right]=0} \\
(\lambda J+M)\left[\begin{array}{c}
m_{2} \\
n_{2}
\end{array}\right]=\left[\lambda_{2}\left[\begin{array}{ll}
1 & 0 \\
0 & 1
\end{array}\right]+\left[\begin{array}{ll}
v & w \\
x & 0
\end{array}\right]\right]\left[\begin{array}{c}
m_{2} \\
n_{2}
\end{array}\right]=0 \\
{\left[\begin{array}{cc}
v+\lambda_{2} & w \\
x & \lambda_{2}
\end{array}\right]\left[\begin{array}{c}
m_{2} \\
n_{2}
\end{array}\right]=0}
\end{gathered}
$$

SO

$$
\begin{aligned}
& m_{1}=-\frac{n_{1} w}{v+\lambda_{1}} \\
& m_{2}=-\frac{n_{2} w}{v+\lambda_{2}}
\end{aligned}
$$

now let

$$
\begin{aligned}
& m_{1}=A_{1} \\
& m_{2}=A_{2}
\end{aligned}
$$

which implies

$$
\begin{aligned}
& n_{1}=-\left(\frac{v+\lambda_{1}}{w}\right) A_{1} \\
& n_{2}=-\left(\frac{v+\lambda_{2}}{w}\right) A_{2}
\end{aligned}
$$

the complementary functions can now be written

$$
\left[\begin{array}{l}
p_{c} \\
c_{c}
\end{array}\right]=\left[\begin{array}{c}
\sum_{i} m_{i} e^{\lambda_{i} t} \\
\sum_{i} n_{i} e^{\lambda_{i} t}
\end{array}\right]=\left[\begin{array}{c}
A_{1} e^{\lambda_{1} t}+A_{2} e^{\lambda_{2} t} \\
-\left(\frac{v+\lambda_{1}}{w}\right) A_{1} e^{\lambda_{1} t}-\left(\frac{v+\lambda_{2}}{w}\right) A_{2} e^{\lambda_{2} t}
\end{array}\right]
$$

so the solutions are

$$
\begin{aligned}
& p(t)=p_{c}+\bar{p}=A_{1} e^{\lambda_{1} t}+A_{2} e^{\lambda_{2} t}+\bar{p} \\
& c(t)=c_{c}+\bar{c}=-\left(\frac{v+\lambda_{1}}{w}\right) A_{1} e^{\lambda_{1} t}-\left(\frac{v+\lambda_{2}}{w}\right) A_{2} e^{\lambda_{2} t}+\bar{c} .
\end{aligned}
$$


The stable branch is associated with the root

$$
=\frac{\lambda_{2}=\frac{-v-\sqrt{v^{2}+4 x w}}{2}}{2-\sqrt{r^{2}+4\left(\left(\frac{1}{\theta-1}\right)\left(\beta(\beta-1)\left(\frac{\beta}{\delta+r}\right)^{\frac{\beta-2}{1-\beta}}\left(e^{-r \omega}\right)^{-\frac{\beta}{1-\beta}}\right)(\bar{c}-1)\right)}}<0
$$

and thus the stable branch has slope

$$
\frac{d c(t)}{d p(t)}=-\left(\frac{v-\sqrt{v^{2}+4 x w}}{2 w}\right)
$$

it follows that the stable branch is approximated locally by

$$
c(t)=\left[\bar{c}+\left(\frac{v-\sqrt{v^{2}+4 x w}}{2 w}\right) \bar{p}\right]-\left(\frac{v-\sqrt{v^{2}+4 x w}}{2 w}\right) p(t)
$$

which may be rewritten using the definitions of $\lambda_{2}$ and $w$ as

$$
c(t)=\left[\bar{c}+\left(\frac{\lambda_{2}-r}{e^{-r \omega}}\right) \bar{p}\right]-\left(\frac{\lambda_{2}-r}{e^{-r \omega}}\right) p(t),
$$

which is $(25)$ in the text.

Now we can select any point on the saddle path as our initial condition so choose

$$
\begin{gathered}
p(0) \\
c(0)=\bar{c}+\left(\frac{v+\lambda_{2}}{w}\right) \bar{p}-\left(\frac{v+\lambda_{2}}{w}\right) p(0)
\end{gathered}
$$

Also for saddle path stability it must be $A_{1}=0$ (or the equilibrium cannot be stable), so evaluating the solutions at $t=0$ gives

$$
A_{2}=p(0)-\bar{p}
$$

which eliminates the arbitrary constant. The particular solution is thus

$$
\begin{aligned}
& p(t)=(p(0)-\bar{p}) e^{\lambda_{2} t}+\bar{p}=e^{\lambda_{2} t} p(0)+\left(1-e^{\lambda_{2} t}\right) \bar{p} \\
& c(t)=-\left(\frac{v+\lambda_{2}}{w}\right)(p(0)-\bar{p}) e^{\lambda_{2} t}+\bar{c}
\end{aligned}
$$

which are our solution to the linearized system (24) and (25).

\subsection{Steady State Corruption Measures.}

From (21) we have the steady state public capital stock $\bar{p}=\left(\frac{\beta e^{-r \omega}}{\delta+r}\right)^{\frac{1}{1-\beta}}$, hence from this and (1) the steady state output level is $\bar{y}=\left(\frac{\beta e^{-r \omega}}{\delta+r}\right)^{\frac{\beta}{1-\beta}}$. Further, from (20) the steady state consumption level is

$$
\bar{c}=\left[\left(\frac{\beta}{\delta+r}\right)^{\frac{\beta}{1-\beta}}-\delta\left(\frac{\beta}{\delta+r}\right)^{\frac{1}{1-\beta}}\right]\left(e^{-r \omega}\right)^{\frac{\beta}{1-\beta}} \text {. Now from (12) } \bar{\tau} e^{-r \omega}=\delta \bar{p} \text { and from }(11) \bar{b}=\left(1-e^{-r \omega}\right) \bar{\tau} \text {. }
$$

Combining these expression we have

$$
\frac{\bar{b}}{\bar{y}}=\frac{\left(1-e^{-r \omega}\right)\left(\frac{\delta \bar{p}}{e^{-r \omega}}\right)}{\left(\frac{\beta e^{-r \omega}}{\delta+r}\right)^{\frac{\beta}{1-\beta}}}=\left(1-e^{-r \omega}\right)\left(\frac{\delta \beta}{\delta+r}\right),
$$




$$
\frac{\bar{b}}{\bar{\tau}}=\frac{\left(1-e^{-r \omega}\right)\left(\frac{\delta \bar{p}}{e^{-r \omega}}\right)}{\left(\frac{\delta \bar{p}}{e^{-r \omega}}\right)}=\left(1-e^{-r \omega}\right)
$$

and

$$
\overline{\bar{b}}=\frac{\left(1-e^{-r \omega}\right)\left(\frac{\delta \bar{p}}{e^{-r \omega}}\right)}{\left[\left(\frac{\beta}{\delta+r}\right)^{\frac{\beta}{1-\beta}}-\delta\left(\frac{\beta}{\delta+r}\right)^{\frac{1}{1-\beta}}\right]\left(e^{-r \omega}\right)^{\frac{\beta}{1-\beta}}}=\frac{\left(1-e^{-r \omega}\right) \delta}{\frac{\delta+r}{\beta}-\delta} .
$$

which are expressions (27)-(29) in the text.

\subsection{The Dynamics of Corruption.}

\subsubsection{Total Corruption.}

Differentiating the linearized saddle path system (24) and (25) with respect to time gives the dynamics along the saddle path

$$
\begin{aligned}
& \dot{p}(t)=(p(0)-\bar{p}) \lambda_{2} e^{\lambda_{2} t}>0 \\
& \dot{c}(t)=-\left(\frac{v+\lambda_{2}}{w}\right)(p(0)-\bar{p}) \lambda_{2} e^{\lambda_{2} t}>0
\end{aligned}
$$

Now using the differential equation constraint (12) and substituting in for $\dot{p}(t)$ provides

$$
\tau(t)=\frac{\left(\lambda_{2}+\delta\right)(p(0)-\bar{p}) \lambda_{2} e^{\lambda_{2} t}+\delta \bar{p}}{e^{-r \omega}}
$$

and

$$
\tau(t+\omega)=\frac{\left(\lambda_{2}+\delta\right)(p(0)-\bar{p}) \lambda_{2} e^{\lambda_{2}(t+\omega)}+\delta \bar{p}}{e^{-r \omega}} .
$$

Now since

$$
b(t)=\tau(t)-e^{-r \omega} \tau(t+\omega)
$$

substitution gives us

$$
\begin{aligned}
b(t) & =\frac{\left(\lambda_{2}+\delta\right)(p(0)-\bar{p}) \lambda_{2} e^{\lambda_{2} t}+\delta \bar{p}}{e^{-r \omega}}-\left(\lambda_{2}+\delta\right)(p(0)-\bar{p}) \lambda_{2} e^{\lambda_{2}(t+\omega)}+\delta \bar{p} \\
& =\left(\lambda_{2}+\delta\right)(p(0)-\bar{p}) \lambda_{2} e^{\lambda_{2} t}\left[e^{r \omega}-e^{\lambda_{2} \omega}\right]+\delta \bar{p}\left(e^{r \omega}-1\right) .
\end{aligned}
$$

Differentiating with respect to time yields

$$
\begin{aligned}
\dot{b}(t) & =\left(\lambda_{2}+\delta\right)(p(0)-\bar{p})\left(\lambda_{2}\right)^{2}\left[e^{\lambda_{2} t+r \omega}-e^{\lambda_{2}(t+\omega)}\right] \\
& =\left(\lambda_{2}+\delta\right)(p(0)-\bar{p})\left(\lambda_{2}\right)^{2} e^{\lambda_{2} t}\left[e^{r \omega}-e^{\lambda_{2} \omega}\right]>0,
\end{aligned}
$$

and again gives

$$
\ddot{b}(t)=\left(\lambda_{2}+\delta\right)(p(0)-\bar{p})\left(\lambda_{2}\right)^{3} e^{\lambda_{2} t}\left[e^{r \omega}-e^{\lambda_{2} \omega}\right]<0 .
$$

Hence we have equations (32)-(34) in the text.

\subsubsection{Corruption as a Share of Output.}

Substituting for $p(t)$ from (24) into (1) gives

$$
y(t)=\left[e^{\lambda_{2} t} p(0)+\left(1-e^{\lambda_{2} t}\right) \bar{p}\right]^{\beta}
$$


then dividing the expression for $b(t)$ from above by this gives

$$
\begin{aligned}
\left(\frac{b(t)}{y(t)}\right) & =\left[\left(\lambda_{2}+\delta\right)(p(0)-\bar{p}) \lambda_{2} e^{\lambda_{2} t}\left[e^{r \omega}-e^{\lambda_{2} \omega}\right]+\delta \bar{p}\left(e^{r \omega}-1\right)\right]\left[\frac{1}{e^{\lambda_{2} t} p(0)+\left(1-e^{\lambda_{2} t}\right) \bar{p}}\right]^{\beta} \\
& =\left[\left(\lambda_{2}+\delta\right)(p(0)-\bar{p}) \lambda_{2} e^{\lambda_{2} t}\left[e^{r \omega}-e^{\lambda_{2} \omega}\right]+\delta \bar{p}\left(e^{r \omega}-1\right)\right]\left[e^{\lambda_{2} t} p(0)+\left(1-e^{\lambda_{2} t}\right) \bar{p}\right]^{-\beta}
\end{aligned}
$$

which is (35) in the text.

Differentiating with respect to time gives us

$$
\begin{aligned}
\left(\frac{b(t)}{y(t)}\right)= & \left(\lambda_{2}+\delta\right)(p(0)-\bar{p})\left(\lambda_{2}\right)^{2} e^{\lambda_{2} t}\left[e^{r \omega}-e^{\lambda_{2} \omega}\right]\left[e^{\lambda_{2} t} p(0)+\left(1-e^{\lambda_{2} t}\right) \bar{p}\right]^{-\beta} \\
& -\beta\left[e^{\lambda_{2} t} p(0)+\left(1-e^{\lambda_{2} t}\right) \bar{p}\right]^{-(1+\beta)}[p(0)-\bar{p}] \lambda_{2} e^{\lambda_{2} t} \\
& \times\left[\left(\lambda_{2}+\delta\right)(p(0)-\bar{p}) \lambda_{2} e^{\lambda_{2} t}\left[e^{r \omega}-e^{\lambda_{2} \omega}\right]+\delta \bar{p}\left(e^{r \omega}-1\right)\right] \gtreqless 0
\end{aligned}
$$

which is (36) in the text.

To study this equation note that

$$
\begin{aligned}
\operatorname{sgn}\left(\frac{\dot{b(t)}}{y(t)}\right)= & \operatorname{sgn}\left\{\left[\left(\lambda_{2}+\delta\right) \lambda_{2}\left(e^{r \omega}-e^{\lambda_{2} \omega}\right)\right]\left[e^{\lambda_{2} t}(p(0)-\bar{p})+\bar{p}\right]\right. \\
& \left.-\beta\left[\left(\lambda_{2}+\delta\right)(p(0)-\bar{p}) \lambda_{2} e^{\lambda_{2} t}\left(e^{r \omega}-e^{\lambda_{2} \omega}\right)+\delta \bar{p}\left(e^{r \omega}-1\right)\right]\right\},
\end{aligned}
$$

hence as $t \rightarrow \infty$

$$
\operatorname{sgn}\left(\frac{b(t)}{y(t)}\right) \rightarrow \operatorname{sgn}\left\{\left[\left(\lambda_{2}+\delta\right) \lambda_{2}\left(e^{r \omega}-e^{\lambda_{2} \omega}\right)-\beta \delta\left(e^{r \omega}-1\right)\right] \bar{p}\right\} \gtreqless 0
$$

and as $t \rightarrow 0$

$$
\begin{gathered}
\operatorname{sgn}\left(\frac{\dot{b(t)}}{y(t)}\right) \rightarrow \operatorname{sgn}\left\{(1-\beta)\left[\left(\lambda_{2}+\delta\right) \lambda_{2}\left(e^{r \omega}-e^{\lambda_{2} \omega}\right)\right] p(0)\right. \\
\left.+\beta\left[\left(\lambda_{2}+\delta\right) \lambda_{2}\left(e^{r \omega}-e^{\lambda_{2} \omega}\right)+\delta\left(e^{r \omega}-1\right)\right] \bar{p}\right\}>0
\end{gathered}
$$

which provides the possibilities illustrated in figure 2 .

\subsubsection{Derivation of expression (40).}

Taking the time derivative of the production function gives $\dot{y}(t)=\dot{p}(t) \beta p(t)^{\beta-1}$ dividing this by the production function gives

$$
\frac{\dot{y}(t)}{y(t)}=\beta\left(\frac{\dot{p}(t)}{p(t)}\right)
$$

Substituting into this expression from (24) and using $\dot{p}(t)=(p(0)-\bar{p}) \lambda_{2} e^{\lambda_{2} t}$ give us

$$
\frac{\dot{y}(t)}{y(t)}=\beta\left(\frac{(p(0)-\bar{p}) \lambda_{2} e^{\lambda_{2} t}}{(p(0)-\bar{p}) e^{\lambda_{2} t}+\bar{p}}\right) .
$$

Now from (32) we have $b(t)=\left(\lambda_{2}+\delta\right)(p(0)-\bar{p}) \lambda_{2} e^{\lambda_{2} t}\left[e^{r \omega}-e^{\lambda_{2} \omega}\right]+\delta \bar{p}\left(e^{r \omega}-1\right)$, rearranging this and substituting into the growth rate expression for $(p(0)-\bar{p}) \lambda_{2} e^{\lambda_{2} t}$ gives

$$
\frac{\dot{y}(t)}{y(t)}=\left[\frac{\beta}{(p(0)-\bar{p}) e^{\lambda_{2} t}+\bar{p}}\right]\left[\frac{b(t)-\delta \bar{p}\left(e^{r \omega}-1\right)}{\left(\lambda_{2}+\delta\right)\left(e^{r \omega}-e^{\lambda_{2} \omega}\right)}\right]
$$

as required. 


\section{References}

[1] Abbott, Elizabeth, "Haiti: The Duvalliers and Their Legacy," (New York: McGraw-Hill) 1988.

[2] Acemoglu, Daren, and Thierry Verdier, "The Choice between Market Failure and Corruption," American Economic Review, Vol. 90, No. 1. (March 2000), pp 194-211.

[3] Anvig, Jens C., and Karl Ove Moene, "How Corruption May Corrupt," Journal of Economic Behavior and Organization, Vol 13, (1990), pp. 63-76.

[4] Barreto, Raul A., "Endogenous Corruption in a Neoclassical Growth Model," European Economic Review, Vol 44, (2000), pp 35-60.

[5] Barro, Robert J., "Government Spending in a Simple Model of Endogenous Growth," The Journal of Political Economy, Vol. 98, No. 5, Part 2: The Problem of Development: A Conference of the Institute for the Study of Free Enterprise Systems. (Oct., 1990), pp. S103-S125.

[6] Besley, Timothy and Stephen Coate, "An Economic Model of Representative Democracy," The Quarterly Journal of Economics, Vol. 112, No. 1. (Feb., 1997), pp. 85-114.

[7] Campos, Nauro F., and Fabrizio Coricelli, "Growth in Transition: What We Know, What We Don't, and What We Should," Journal of Economic Literature, Vol. XL (Sept. 2002), pp 793-836.

[8] Ehrlich, Isaac and Francis T. Lui, "Bureaucratic Corruption and Endogenous Economic Growth," The Journal of Political Economy, vol 107, No. 2 (Dec. 1999).

[9] Hall, Robert E. and Charles I. Jones, "Levels of Economic Activity Across Countries," American Economic Review, Vol. 87, No. 2. (May 1997), pp 173-177.

[10] Hall, Robert E. and Charles I. Jones, "Why Do Some Countries Produce so Much More Output per Worker than Others.," The Quarterly Journal of Economics, Vol. 114, No. 1. (Feb., 1999), pp. 83-116.

[11] Kopits, George, and Jon Craig, "Transparency in Government Operations," IMF Occasional Paper 158, 1998.

[12] Graf Lambsdorff, Johann, "Corruption in Empirical Research," Transparency International Working Paper 1999.

[13] Mauro, Paolo, "Corruption and Growth," The Quarterly Journal of Economics, Vol. 110, No. 3. (Aug., 1995), pp. 681-712.

[14] _ , "The Effects of Corruption on Growth, Investment, and Government Expenditure," IMF Working Paper No. 96/98, (Sept. 1996).

[15] — "The Persistence of Corruption and Slow Economic Growth," IMF Working Paper No. 2/213, (Dec. 2002).

[16] Olson, Mancur, "Distinguished Lecture on Economics in Government: Big Bills Left on the Sidewalk: Why Some Nations are Rich and Others Poor," The Journal of Economic Perspectives, Vol 10, No. 2, (Spring 1996), pp 2-24.

[17] Osborne, Martin J. and Al Slivinski, "A Model of Political Competition with Citizen-Candidates," The Quarterly Journal of Economics, Vol. 111, No. 1. (Feb., 1996), pp. 65-96.

[18] Rosen, Harvey, S., "Public Finance," (Chicago: Irwin) 1995.

[19] Ritva Reinikka, and Jakob Svensson, "Explaining Leakage of Public Funds," World Bank Working Paper No. 2709, (Oct. 2001).

[20] Rosenbleuth, Javier, "Infinite Time Problems with Shifted and Delayed Controls," Applied Mathematics Letters, No. 8, (1995) pp. 3-36. 
[21] Shleifer, Andrei and Robert W. Vishny, "Corruption," The Quarterly Journal of Economics, Vol. 108, No. 3. (Aug., 1993), pp. 599-617.

[22] Tanzi, Vito and Davoodi, Hamidm,"Corruption, Public Investment, and Growth," IMF Working Paper No. 97/139 (Oct.1997).

[23] Tanzi, Vito,"Corruption Around the World: Causes Consequences, Scope, and Cures," IMF Working Paper No. 98/63 (May.1998).

[24] World Bank, "World Development Report 1997: The State in a Changing World," (Oxford University Press), 1997. 